\title{
La evaluación de los riesgos ambientales y su aplicación a los proyectos de desarrollo limpio
}

\author{
Alfredo Cabezas Ares \\ Profesor del CES Felipe II. Campus de la Universidad \\ Complutense de Madrid en Aranjuez. \\ alfredo.cabezas@cesfelipesegundo.com
}

\begin{abstract}
RESUMEN
La ONU a través del PNUMA está auspiciando la financiación de proyectos de inversión que supongan una reducción de la Emisión de Gases de Efecto Invernadero o su absorción. Muchos de estos proyectos se ubican en países en vías de desarrollo, lo cual en esencia es beneficioso desde el punto de vista económico especialmente para las ubicaciones seleccionadas. En este trabajo se estudia como evaluar los riesgos ambientales de los proyectos de Desarrollo Limpio, teniendo especial consideración de su emplazamiento, su actividad y las sustancias utilizadas.

Palabras clave: evaluación de riesgos medioambientales, proyectos de inversión MDL, derechos de emisión.
\end{abstract}

Clasificación JEL: Q55, Q56, Q58.

\begin{abstract}
The United Nations Environmental Program (UNEP) is promoting the financing of investment projects that involve a reduction in the absorption or emission of Greenhouse Gases. Many of these projects are located in developing countries, obviously they have positive economical effects especially for selected locations. In this
\end{abstract}


paper we study the environmental risks of the Clean Development Mechanism projects, taking special consideration of their location, activity and the substances used.

Keywords: environmental risk assessment, CDM investment projects, emission rights.

JEL Classification: Q55, Q56, Q58.

Abreviaturas utilizadas

AC Acción Conjunta

BAT Best Available Technologies

GEI Gases de Efecto Invernadero

MDL Mecanismo de Desarrollo Limpio

RCEs Reducción Certificada de Emisiones

UNEP United Nations Environmental Program

UNFCCC United Nations Framework Convention on Climate Change

UREs Unidades de Reducción de Emisiones

\section{INTRODUCCIÓN}

En los últimos años se ha tratado de estimar, de muy diferentes maneras, la repercusión de las actividades productivas sobre el medio ambiente, la contaminación por ellas emitida o los daños ambientales que producen.

Estas estimaciones han puesto de manifiesto la importancia de las actividades productivas en relación con la emisión de grandes cantidades de contaminantes y su indudable impacto sobre todos los medios. Así ya en 1999 la Agencia Europea del Medio Ambiente $^{1}$ estimaba que la industria interacciona en once de los doce problemas ambientales mas graves de la Unión Europea, es decir, tiene una influencia muy significativa sobre el cambio climático, el ozono estratosférico, la acidificación, el ozono troposférico, las sustancias químicas, la generación de residuos, la contaminación de las aguas, las zonas marítimas y el litoral, los suelos, el medio ambiente urbano, la generación de riesgos ecológicos y la amplificación de los riesgos naturales.

1 Agencia Europea de Medio Ambiente (1999): El Medio Ambiente en la Unión Europea en el umbral del Siglo XXI; resumen. Copenhague. http://www.eea.eu.int 
Para abordar los problemas ambientales la UE ha puesto en marcha los Programas de Acción de la Comunidad Europea en Materia de Medio Ambiente, conocidos como PAMA. Actualmente está en ejecución el Sexto Programa ${ }^{2}$, que establece la estrategia comunitaria para un período que abarca hasta el 2012, con cuatro objetivos prioritarios:

- Cambio climático.

- Naturaleza y biodiversidad.

- Medio ambiente y salud.

— Utilización sostenible de los recursos naturales y gestión de residuos.

En este trabajo se analizan las relaciones entre las actividades productivas y el medio ambiente desde la perspectiva del riesgo, su medición y evaluación, centrándose en los proyectos a realizar en países emergentes o en desarrollo, que instauran proyectos respetuosos con el medio ambiente.

Por otra parte, es de destacar el impulso dado por organizaciones internacionales, tales como, UNEP-PNUMA ( United Nations Environment Program ), para la puesta en marcha de proyectos de inversión de actividades productivas con importantes reducciones de las emisiones a la atmósfera.

La Convención de las Naciones Unidas sobre Cambio Climático, tiene como objetivo la estabilización de las concentraciones de gases de efecto invernadero en la atmósfera. Este objetivo se concreta aún más en el Protocolo de Kyoto, al promover su reducción por parte de los países industrializados.

En la línea de lograr un desarrollo sostenible a nivel mundial, es necesario reducir las emisiones a la atmósfera y potenciar la absorción de los gases de efecto invernadero emitidos. La viabilidad técnica y económica de este tipo de proyectos difiere en gran medida de unos países a otros.

Por otra parte la Unión Europea y sus Estados Miembros, han ratificado la Convención Marco de las Naciones Unidas sobre el cambio Climático (UNFCCC), y el Protocolo de Kyoto. Además a nivel europeo se articulan las medidas necesarias para

${ }^{2}$ Unión Europea (2001): Sexto Programa de Acción de la Comunidad Europea en materia de Medio Ambiente: «Medio Ambiente 2010: el futuro está en nuestras manos». COM (2001) 31 final. http://europa.eu.int/comm/environment/newprg/index.htm 
poder cumplir los compromisos de emisión establecidos en el protocolo de $\mathrm{Kyoto}^{3}$ y se establecen nuevos compromisos para los períodos postKyoto ${ }^{4}$.

Estas acciones han conllevado, tanto el conocimiento de los problemas medioambientales y la necesidad de reducir y limitar dichas emisiones, como la puesta en marcha de un complejo mercado de derechos de emisión. Llegando a acuerdos internacionales, que suscriban la mayor parte de países, las limitaciones de emisiones serán más efectivas a nivel mundial.

Ha sido necesario contemplar la situación de los países con economías de transición y de los países en proceso desarrollo, buscando equilibrios a veces complicados, dado que hasta ahora los países del primer mundo, han conseguido crecimientos importantes de sus economías a base de presionar sobre el medio ambiente, con un grado de contaminación importante. Y esto no debe ser una barrera insalvable para el desarrollo de los países emergentes en los momentos actuales y futuros.

Las soluciones adoptadas facilitan la inversión en nuevos proyectos en estos países, con transferencia de tecnología en el marco de las Best Available Technologies, buscando disminuir las emisiones, sin limitar el desarrollo económico de estos países.

Así se ha creado el Clean Development Mechanism (en adelante $M D L$ ), como un instrumento financiero, auspiciado por el UNFCCC, que promueve las inversiones en países sin limitación de emisiones ${ }^{5}$ en los que se instauren tecnologías limpias, con importantes ahorros en la emisión a la atmósfera, permitiendo que las unidades de carbono no emitidas, puedan ser vendidas en los mercados de carbono o trasladadas a otros países para poder emitir más unidades de las inicialmente asignadas por el Estado.

Este mecanismo está movilizando la inversión extranjera hacia estos países y materializándose en proyectos más respetuosos con el medio ambiente. Por otra parte, con

${ }^{3}$ http://ec.europa.eu/environment/climat/eccp_impacts.htm

${ }^{4}$ Legislación/ Unión Europea: Directiva No 2009/29/CE del Parlamento Europeo y del Consejo Europeo, de 23 de abril de 2009, por el que se modifica la Directiva2003/87/CE para perfeccionar y ampliar el régimen comunitario de comercio de derechos de emisión de gases de efecto invernadero. DOCE, $\mathrm{N}^{\circ}$ L 140, de 05/06/2009.

${ }^{5}$ Los países con limitaciones de emisiones son los enumerados en el Anexo 1 de la Convención Marco de las Naciones Unidas sobre el Cambio Climático: Alemania, Australia, Austria, Bielorrusia, Bélgica, Bulgaria, Canadá, Croacia, Comunidad Económica Europea, Dinamarca, Eslovaquia, Eslovenia, España, Estados Unidos de América, Estonia, Federación de Rusia, Finlandia, Francia, Grecia, Hungría, Irlanda, Islandia, Italia, Japón, Letonia, Lituania, Liechtenstein, Luxemburgo, Mónaco, Noruega, Nueva Zelanda, Países Bajos, Polonia, Portugal, Reino Unido de Gran Bretaña e Irlanda del Norte, República Checa, Rumania, Suecia, Suiza, Turquía y Ucrania. 
la puesta en marcha del mercado de carbono los proyectos MDL obtienen una fuente de financiación adicional que aumenta su rentabilidad. Todo ello no sólo supone de por si una mejora económica para el desarrollo de estos países, sino que además consigue la implantación de tecnologías de última generación en zonas a las que de otra manera tardarían varias décadas en llegar.

En el marco del comercio de los derechos de emisión de la Unión Europea, un derecho de emisión es una autorización, concedida por un Estado Miembro, al titular de una instalación, localizada en dicho estado, para que, desde la misma pueda emitir una tonelada de dióxido de carbono equivalente $(\mathrm{CO} 2 \mathrm{e})$ durante un año natural determinado ${ }^{6}$.

En la UE hay un Plan de Asignación Europeo en el que identifica las instalaciones afectadas y la cantidad máxima de toneladas de $\mathrm{CO} 2$ e que puede emitir anualmente cada una de ellas. Mediante la obligación de entregar, cada año, los derechos correspondientes a las emisiones de realizadas, las empresas se ven obligadas a reducir sus emisiones, como mínimo a la cantidad asignada, o bien a obtener una cantidad mayor de derechos de emisión.

Por otra parte, los mecanismos basados en proyectos del Protocolo de Kyoto permiten la generación de unidades de carbono a cambio de reducciones reales producidas en proyectos concretos realizados:

a) En países sin limite de emisiones, mediante el Mecanismo para un desarrollo limpio (MDL), generando las unidades de carbono denominadas RCEs (reducciones certificadas de emisiones).

b) En países con emisiones limitadas, a través del Mecanismo de Acción Conjunta (AC), generando las unidades de carbono denominadas UREs (Unidades de reducción de emisiones).

El sistema europeo permite canjear este tipo de unidades de carbono (RCEs y UREs) por derechos de emisión europeos, dentro de unos límites tanto cualitativos como cuantitativos, incrementando así la liquidez de las unidades de carbono en el mercado y ayudando a reducir su precio.

${ }^{6}$ Art. 3 de la Directiva 2003/87/CE del Parlamento Europeo y del Consejo, de 13 de octubre de 2003, por la que se establece un régimen para el comercio de derechos de emisión de gases de efecto invernadero en la Comunidad y por la que se modifica la Directiva 96/61/CE del Consejo 
El Objeto de este trabajo es caracterizar el riesgo ambiental y sus alternativas de gestión, a fin de facilitar la selección de proyectos cuya prioridad es obtener unidades de carbono canjeables por derechos de emisión. Se trata de proyectos en los que los inversores o promotores pertenecen a países con emisiones de GEI limitadas, mientras que los países anfitriones no tienen limitaciones de emisiones y estos proyectos resultan viables teniendo en cuenta el impacto económico, financiero, jurídico y técnico de los riesgos ambientales intrínsecos de la inversión.

\section{RiEsGo ACEPTABle}

La Unión Europea ha ido cambiando gradualmente la concepción de las normativas y políticas ambientales, basadas inicialmente en el concepto de peligros a asumir el concepto de riesgo, fijando la atención en el estudio de los riesgos ambientales reales en lugar de dirigirse a los peligros potenciales que pueden o no surgir.

La forma de abordar los problemas que presentan los suelos contaminados con compuestos tóxicos constituye un buen ejemplo de ello. Un enfoque basado en los peligros consiste en identificar los compuestos tóxicos del suelo y establecer las medidas correctoras para reducir las concentraciones de los mismos hasta niveles aceptables. Un enfoque basado en los riesgos comienza por identificar estos compuestos y toma en consideración que el nivel de limpieza necesario depende de la probabilidad de que haya personas expuestas a los mismos y de los posibles efectos provocados por el nivel de exposición. En este segundo caso, el grado de descontaminación depende fundamentalmente del uso del suelo y de los riesgos que conlleva dicho uso.

Esta misma tendencia también se observa en la actuación de la Environmental Protection Agency (EPA) ${ }^{7}$ norteamericana cuando diseña las actividades a desarrollar para descontaminar 1.270 suelos contaminados de actuación prioritaria (National Priority List), del total de 36.000 lugares contaminados identificados en su ámbito territorial de actuación en junio de 1993.

Esta tendencia hacia la elaboración y análisis de información basada en el riesgo, supone reconocer que, para algunas cuestiones ambientales, no existirán soluciones que comporten riesgo cero y que la búsqueda de una seguridad plena implica, con frecuencia, costes excesivos por tratar de alcanzar niveles no necesarios para proteger a los seres humanos y a los ecosistemas.

7 Snayder y Smith (1994): «The Industry's Black Hole», Best’s Review. mayo, págs. 9 y 11 
De esta forma, se consolida el concepto de riesgo ambiental aceptable o riesgo que se encuentra por debajo de un determinado umbral o límite previamente establecido, y la aceptación de la inexistencia de riesgo cero ${ }^{8}$. Ello supone aceptar que no existe un nivel de seguridad total ó riesgo cero para los agentes que pueden repercutir sobre la salud humana y sobre los ecosistemas.

El hecho de adoptar el nivel de riesgo, como criterio para seleccionar prioridades, da lugar a un análisis comparativo de los riesgos, a fin de establecer un orden de actuación.

\section{ANÁLISIS DE RIESGOS AMBIENTALES}

El análisis de riesgos ambientales consiste ${ }^{9}$, en la determinación, con una precisión razonable, de los accidentes que pueden ocurrir, su frecuencia y la magnitud de sus consecuencias, siendo los instrumentos mas utilizados en este ámbito los siguientes ${ }^{10}$ :

a) Tratamiento probabilístico.

b) Tratamiento determinístico.

c) Índices estadísticos de riesgo.

Para evaluar el riesgo se estudian tanto los acontecimientos internos, originados dentro de las instalaciones propias, como los acontecimientos externos de origen natural (terremotos, inundaciones, etc.) o artificial (explosiones, incendios, ocurridos en industrias próximas, carretera, etc.), capaces de originar posteriores emergencias internas. En la utilización de los tres instrumentos indicados hay importantes factores que incluyen juicios de valor y por tanto apreciaciones eminentemente subjetivas, tales como la percepción individual y social del riesgo analizado.

${ }^{8}$ Landulce (1991): «El riesgo de un accidente es imposible llevarlo a cero», Química Hoy. enero, núm. 8 págs. $45-47$

9 Instituto de Investigaciones Ecológicas (1997): Consultoría y Verificación Medioambiental, Málaga Centauro, vol. 5, págs. 114 y 115

10 Véase Cabezas Ares (2003): Los Seguros de Responsabilidad Civil Medioambiental en la Industria, León. Servicio de Imprenta, Secretariado de Publicaciones y Medios Audiovisuales, Universidad de León. 
El análisis de riesgos introducido por Davies ${ }^{11}$ se fundamenta en el análisis comparativo de riesgos, su evaluación, su gestión y la comunicación de la información sobre los mismos, que se analizan seguidamente. El análisis comparativo de riesgos atiende a dos o más tipos de riesgos, bien definidos, a fin de conocer sus diferencias y semejanzas. Esto supone analizar riesgos de fuentes similares (por ejemplo, el riesgo de cáncer de dos tipos de pesticidas) ó diferentes (por ejemplo, el riesgo de muerte por un accidente de tráfico y el riesgo de muerte por exposición al benceno). Este tipo de análisis de riesgos suele ser muy efectivo cuando las fuentes que generan los riesgos comparados son similares.

Davies establece las siguientes categorías a las que aplicar el análisis comparativo de riesgos:

- Selección de programas ambientales.

- Áreas geográficas de actuación prioritaria.

- Problemas específicos de una determinada zona geográfica

- Propuestas de acción dentro de una instalación, por ejemplo la sustitución de un elemento por otro.

- Fuentes de la contaminación y sectores económicos afectados por la contaminación.

- Población afectada.

Con la presentación, al Senado Norteamericano, del informe Unfinished Business ${ }^{12}$, de la Environmental Protection Agency (EPA), aumenta notablemente la difusión del análisis comparativo de riesgos, ya que proporciona un marco conceptual para el establecimiento de prioridades ambientales. Inicialmente se aplicó al diseño de políticas ambientales y su debate público. En la actualidad también se aplica para establecer prioridades presupuestarias y establecer comparaciones entre una gran variedad de riesgos.

Como se ha indicado, este tipo de análisis está sujeto a juicios de valor y por lo tanto suele conllevar una decisión política. Ante el establecimiento de prioridades presupuestarias, con un criterio de economicidad, en la gestión ambiental, el análisis comparativo

11 Davies (1996): Comparing Environmental Risks: Tools for Setting Government Priorities, Washington, Resources for the Future, pág. 13

12 Enviromental Protection Agency (EPA). Office of Policy Analysis (1987): Unfinished Business: A Comparative Assessment of Environmental Problems, Washington, D.C., Ed U.S. EPA. 
A LOS PROYECTOS DE DESARROLLO LIMPIO

de riesgos permite tener en cuenta el objetivo de maximización de beneficios, a partir de un presupuesto de costes dado, y su dual de minimización presupuestaria de costes, para un nivel de beneficios previamente establecido. Con estos planteamientos, el análisis comparativo de riesgos ha tenido su mayor aceptación en las administraciones públicas y las grandes empresas, en el ámbito de la toma de decisiones entre alternativas de gran trascendencia.

La evaluación del riesgo ambiental consiste en la utilización de técnicas analíticas para determinar el grado de daño que puede esperarse como resultado de un evento y permite estudiar los efectos, crónicos o no, sobre la salud humana y los efectos ecológicos. Una gran parte de las evaluaciones del riesgo ambiental realizadas se caracterizan por un alto grado de incertidumbre, estadísticamente calculada, asociada con enfermedades crónicas (cáncer, efectos congénitos, etc.) en las que se han utilizado diferentes magnitudes. La incertidumbre real es siempre mayor, debido a la controversia sobre las premisas básicas establecidas, tales como la validación de las pruebas realizadas en animales como una vía para la predicción de los riesgos para la salud humana.

La gestión de riesgos considera los factores sociales, económicos y políticos implicados en el análisis de riesgos, determinando la aceptabilidad del posible daño provocado por un evento o exposición y basando cualquier acción en la observación del riesgo derivado de tal daño. En algunas ocasiones la gestión de riesgos se refiere a todo el riesgo considerado en el proceso de toma de decisiones y es, por tanto, más amplio que la evaluación del riesgo, mientras que en otras la gestión de riesgos se limita a la toma de decisiones sobre el riesgo, según se desarrolla posteriormente.

La comunicación de la información sobre riesgos consiste en el suministro de información acerca de dichos riesgos, en función de las necesidades de los usuarios de dicha información y de la confidencialidad requerida por los negocios.

En sus orígenes, esta información se utilizó también para difundir conocimientos sobre un riesgo en particular (por ejemplo, el riesgo de contraer una enfermedad) entre profesionales en la materia. En la actualidad, este tipo de información suele formar parte del intercambio de información entre todos los partícipes de un riesgo, incluido el público en general.

En los Estados Unidos, la evaluación de riesgos se utiliza como concepción técnicoanalítica y objetiva, mientras que la gestión de riesgos es mas subjetiva debido a que en ella se consideran las diferentes opciones que se plantean ante la toma de decisiones.

Esta concepción y delimitación se diluye en Europa, debido a que la parte objetiva y subjetiva del análisis de riesgos se entremezclan y, generalmente, en los análisis de riesgos se aborda su evaluación y su gestión de manera conjunta, tanto en la toma de 
decisiones políticas como en el diseño de la legislación ambiental y su aplicación a la industria.

Para Fairman ${ }^{13}$, la evaluación y la gestión de riesgos presenta las siguientes utilidades y limitaciones:

a) Utilidades

- Cuando es necesario ponderar información muy diversa. La evaluación y la gestión de riesgos es muy útil en el proceso de toma de decisiones políticas que deben considerar información científica, social, económica, etc. En estos casos, las técnicas de evaluación de riesgos sirven de puente entre lo científico y lo social ${ }^{14}$.

- Como mecanismo de ayuda en el proceso de toma de decisiones sobre riesgos, especialmente en la elección entre las distintas opciones de actuación, como por ejemplo las opciones de reducción de riesgos. Una vez establecidos los criterios, los métodos de evaluación y gestión de riesgos ayudarán en el proceso de decisión.

- Como medio de comparación entre distintos riesgos, para determinar si existe proporcionalidad entre la actuación realizada o a realizar y el riesgo planteado.

- Cuando es necesario desglosar sistemas industriales complejos, para identificar partes de ciertos procesos o determinadas instalaciones en las que las medidas de reducción de riesgos pueden resultar más eficaces.

- Como base para la buena comunicación de riesgos. No obstante, cuando el responsable de la comunicación de riesgos desea convencer a un público escéptico ó a un grupo concreto de interés, deberá remitirles a los juicios de valor que subyacen tras la percepción del riesgo.

- Como instrumento para identificar los riesgos a tratar con mayor urgencia y elaborar una jerarquía de prioridades sobre las necesidades de investigación y actuación.

13 Fairman y otros (1998): Evaluación del riesgo Medioambiental: Enfoque, Experiencias y Fuentes de Información, Copenhague, Agencia Europea del Medio Ambiente, págs..24-26

${ }^{14}$ La evaluación de riesgos ambientales, además de considerar los factores técnicos, tiene en cuenta factores sociales. 


\section{b) Limitaciones}

- La evaluación de riesgos puede propiciar un exceso de dependencia y de confianza en los resultados. Esta desventaja se manifiesta sobre todo en los segmentos de riesgo de gran incertidumbre y en los que es frecuente encontrar enfoques conservadores y factores de seguridad. Los que cuestionan la certeza de los métodos de evaluación de riesgos suelen alegar que no es adecuado depender de evaluaciones de riesgos basadas en una metodología incierta.

- Ante un problema determinado, la evaluación de riesgos requiere identificar las partes en que se puede dividir, para centrarse en cada una de estas partes más que en el conjunto del problema. Las evaluaciones de riesgos más frecuentes son las que se ocupan de un agente específico. Las evaluaciones de riesgos relativas a un espacio concreto pueden examinar un conjunto de riesgos, pero cada uno de ellos se debe de aislar para su estudio, pues no existen todavía datos fiables que permitan ocuparse de una combinación de varios agentes.

- Algunos especialistas en medio ambiente y consumo rechazan la evaluación de riesgos debido a la valoración de la vida y de la calidad del medio ambiente que se realizan en multitud de procesos de gestión de riesgos.

- La conjugación del principio de prevención con la evaluación y la gestión de riesgos es, en cierta medida, difícil. Su aplicación supone asumir una postura totalmente preventiva, es decir, puesto que no existe certeza, se llevan a cabo todas las acciones que hipotéticamente podrían prevenir las consecuencias del proceso. Esto se constata ante problemas como el del calentamiento de la Tierra pues, aunque la ausencia de medidas puede tener consecuencias enormes, la acción necesaria para prevenir dicho calentamiento conlleva importantes repercusiones sociales, políticas y económicas, por lo que, en este caso, es inviable conjugar la prevención con la evaluación y la gestión de riesgos ambientales. 


\section{EVALUACIÓN DE RIESGOS MEDIOAMBIENTALES}

\subsection{Delimitación}

Según se ha indicado, la evaluación de riesgos es una metodología de uso habitual en el estudio de los problemas ambientales. El alcance y el ámbito de las evaluaciones de riesgos presentan diversas posibilidades:

a) Abarcar un solo riesgo con distintas hipótesis de exposición

b) Examinar un agente individual, como un contaminante atmosférico o acuático determinado, en un entorno concreto.

c) Estudiar los riesgos ambientales a los que esta expuesta una ciudad, un emplazamiento, etc.

Los métodos de evaluación de riesgos ambientales, tradicionalmente, se han basado en el estudio de los efectos que puede provocar un riesgo ambiental o un accidente sobre el ser humano ${ }^{15}$, aprovechando esta experiencia para abordar otras preocupaciones ambientales.

Por otra parte, el reconocimiento de la importancia de otros daños ambientales, además de aquellos que repercuten sobre el ser humano, ha dado lugar al desarrollo y aplicación de evaluaciones de riesgos ecológicos, es decir, de riesgos que pueden amenazar al conjunto de los organismos vivos presentes en los distintos ecosistemas ${ }^{16}$.

En este ámbito cabe destacar la preocupación de la Organización Mundial de la Salud $^{17}$, al abogar por estudiar las interacciones entre el medio ambiente y la salud, que ha puesto en marcha diversos instrumentos que facilitan el estudio de los efectos de la exposición humana a los contaminantes que hay en el aire, el agua, el suelo, y

15 Por ejemplo en el Informe Dobris. Véase Capítulo 3 Agencia Europea de Medio Ambiente (1998): Medio Ambiente en Europa: El Informe Dobris, Madrid, Oficina de Publicaciones Oficiales de las Comunidades Europeas y Ministerio de Medio Ambiente, Madrid, Edición original editada en 1995.

16 Fairman y otros (1998), Evaluación del riesgo Medioambiental: Enfoque, Experiencias y Fuentes de Información, Copenhague, Agencia Europea del Medio Ambiente, pág. 27.

17 Worls Health Organization (1996): Linkage Methods for Environmental and Health Analysis, Geneve, Office Of Global And Integrated Environmental Health, WHO págs. 1 y 2 
los alimentos (tanto en el corto plazo con exposiciones de gran intensidad, como en el largo plazo en exposiciones continuadas de baja intensidad) y en qué medida son los efectos que mas incrementan la morbilidad y la mortalidad.

La carga de enfermedad atribuible a estas exposiciones presenta un alto grado de incertidumbre, dado que la fluctuación de los niveles de contaminación medioambiental general es elevada, los métodos para analizar las relaciones entre contaminación y salud están desarrollados de forma incompleta y la calidad de los datos disponibles es realmente muy pobre. Por ello se precisan medidas que asocien los niveles de contaminación y sus repercusiones para la salud.

Pero además la exposición a la contaminación es generalmente involuntaria, la gente no suele conocer que ha estado o está expuesta y tampoco los posibles efectos. Como resultado se debe generar un control de sus exposiciones al riesgo.

Ante la incertidumbre que presentan los datos, es posible asumir que las sustancias o los agentes son inocuos mientras no quede demostrado científicamente lo contrario, o bien que los agentes son dañinos mientras no se demuestre científicamente su seguridad. La UE en aplicación de los principios de prevención y de precaución en relación con el medio ambiente, se sitúa en esta segunda posibilidad.

En los últimos años se ha llevado a cabo una actividad considerable en el ámbito de la evaluación de riesgos ambientales, sobre todo en el desarrollo de métodos para la evaluación de riesgos químicos. Debido a la gran cantidad de organizaciones implicadas en el tratamiento empírico de la evaluación de riesgos, existen diversas alternativas que hacen necesaria una armonización.

En esta misma línea se sitúa la $\mathrm{OCDE}^{18}$, al defender que deben continuar los esfuerzos de armonización de las diversas metodologías de evaluación ambiental, en aras a incrementar el uso de la información disponible, así como su intercambio entre los diferentes partícipes.

A pesar del deslinde entre los aspectos técnicos y los aspectos sociales del riesgo ambiental, los resultados de las evaluaciones de riesgos ambientales no gozan de aceptación generalizada. Dado que existen carencias importantes en la calidad o cantidad de la información disponible y que no siempre se ponen de manifiesto (o no se aceptan) las motivaciones que dan lugar al establecimiento de los criterios en que se basan dichas evaluaciones.

18 OCDE (1997): Report of the OECD Workshop on Sharing Information about New Industrial Chemicals Assessment, París, OCDE, pág. 14. 


\subsection{Tipología}

En función de su ámbito, el objeto receptor y los objetivos a alcanzar, las evaluaciones de riesgos ambientales pueden clasificarse como sigue ${ }^{19}$ :

1. Los riesgos que se estudian en la evaluación pueden ser de tipo físico (como las radiaciones) biológico (como los organismos modificados genéticamente o los patógenos) o químicos (como las sustancias inmunotóxicas).

2. El objeto o receptor del estudio en la evaluación de riesgos no siempre es el mismo. El ser humano es la especie más estudiada, si bien las evaluaciones de riesgos también son frecuentes para otras especies singulares. Muchas de las evaluaciones de riesgos ecológicos pueden considerarse evaluaciones relativas a una sola especie, ya que sólo seleccionan como objeto del mismo algunos tipos de organismos representativos.

3. Los objetivos sometidos a examen en las evaluaciones son diversas. En las evaluaciones de riesgos para la salud humana o para otras especies, suelen ser la mortalidad o la morbilidad. Para determinadas evaluaciones de riesgos ecológicos pueden ser la extinción o la captura total de una especie. Para algunas otras se emplean indicadores de biodiversidad o de alteraciones de los sistemas ecológicos.

Entre las diversas alternativas de evaluación de riesgos ambientales (ERA), para nuestro objeto de estudio cabe destacar ${ }^{20}$ :

1. Evaluación de riesgos para la salud humana (ERS)

2. Evaluación de riesgos ecológicos (ERE).

3. Evaluación de riesgos ambientales aplicados a la industria (ERAI).

Aunque las evaluaciones de riesgos para la salud humana (ERS) y las evaluaciones de riesgos ecológicos (ERE) son conceptualmente similares, ambos han experimentado

19 Fairman y otros (1998): Evaluación del riesgo Medioambiental: Enfoque, Experiencias y Fuentes de Informació, Copenhague, AEMA, págs. 27 y 28

${ }^{20}$ Fairman y otros (1998): Evaluación del riesgo Medioambiental: Enfoque, Experiencias y Fuentes de Información, Copenhague, AEMA, pág. 28 
desarrollos históricos distintos y están sometidos a imperativos políticos y normativos diferentes.

Las evaluaciones de riesgos ambientales aplicados a la industria (ERAI) se han separado porque, con frecuencia, no realizan evaluaciones aisladas para las personas o para los sistemas ecológicos, sino que estudian situaciones reales en las que consideran conjuntamente aspectos de diversa índole.

\subsubsection{Evaluación de riesgos para la salud humana (ERS)}

La ERS se utiliza con el fin de estudiar los agentes físicos, químicos y biológicos que pueden afectar al ser humano. El método NAS, que se analiza posteriormente, es el antecedente con mayor influencia dentro de la evaluación de riesgos para la salud, aunque con el tiempo se ha ido adaptando a las necesidades de evaluaciones más específicas. Las técnicas utilizadas en estas evaluaciones están firmemente consolidadas. La ERS toma en consideración a los individuos, fijándose en su morbilidad y su mortalidad.

Entre los diferentes tipos de ERS destacan las evaluaciones de riesgos químicos (que actualmente presentan un gran interés por el posible daño a la salud humana que pueden generar los productos químicos neurotóxicos, inmunotóxicos y cancerígenos) y las que tienen por objeto la identificación de riesgos asociados a la radiación ionizante, los agentes patógenos y los organismos modificados genéticamente.

\subsubsection{Evaluación de riesgos ecológicos (ERE)}

Abarca la evaluación de riesgos generados por las sustancias que el ser humano libera en su entorno y que afectan al conjunto de los organismos vivos presentes en los distintos ecosistemas. Las ERE, generalmente, se orientan hacia la evaluación de los riesgos derivados de las sustancias químicas y de los organismos modificados genéticamente, o bien hacia la evaluación de riesgos físicos, como por ejemplo los aumentos de temperatura provocados por las emisiones de agua de refrigeración de las industrias.

La metodología de la ERE se ha desarrollado a partir de los métodos establecidos para la evaluación de riesgos para la salud humana. En las ERE se fijan poblaciones y comunidades, junto con los efectos que las sustancias ejercen sobre su mortalidad y su fecundidad. Las ERE se dirigen a una multitud de organismos, con diferentes grados 
de sensibilidad a la exposición al riesgo, y a distintos grupos que pueden encontrarse en diferentes escenarios de exposición.

Entre los diferentes tipos de ERE destacan las evaluaciones de productos químicos, de pesticidas y de organismos modificados genéticamente. Actualmente, la ERE se aplica tanto a sustancias legalmente reguladas como a nuevas sustancias.

\subsubsection{Evaluación de riesgos ambientales aplicados a la industria (ERAI)}

Se utiliza con frecuencia dentro del ámbito de la industria europea, pues la ERAI puede resultar una herramienta ventajosa para atender las exigencias legislativas. En la industria química, por ejemplo, es necesario que se evalúen los riesgos de los productos químicos nuevos y los existentes mediante las técnicas impuestas por la Comisión Europea $^{21}$

La mayor parte de las ERAI realizadas se centran en las emisiones accidentales y en las sustancias y productos químicos, ocupando un lugar residual las ERAI relacionadas con las emisiones procedentes de operaciones en condiciones normales, debido a que las emisiones rutinarias están limitadas y controladas por los responsables de la vigilancia del cumplimiento normativo.

Las ERAI suelen incluir evaluaciones de riesgos de carácter técnico y pueden integrar riesgos ecológicos y humanos. Generalmente se suele otorgar una gran importancia al establecimiento de garantías, de forma que la ERAI facilite la toma de decisiones relativas a la gestión, siempre que el objetivo este claramente definido, y el establecimiento de medidas de protección de los seres humanos y del entorno dentro de unos límites geográficos concretos.

${ }^{21}$ Legislación/ Unión Europea: Directiva 82/501/CEE, del Consejo de 24 de junio, relativa a los riesgos de accidentes graves en determinadas actividades industriales DOCE $\mathrm{N}^{\circ} \mathrm{L} 230 \mathrm{de}$ 5/08/1982 Legislación/ Unión Europea: Directiva 96/61/CE del Consejo, de 24 de Septiembre de 1996, relativa a la prevención y control integrados de la contaminación. DOCE No L257 de 10/10/1996. Legislación/ Unión Europea: Directiva 96/82/CE del Consejo, de 9 de Diciembre de 1996, relativa al control y riegos inherentes a los accidentes graves en los que intervengan sustancias peligrosas. DOCE, N L 10, de 14/01/1997. Legislación/ Unión Europea: Directiva del Consejo 75/442/CEE, de 15 de Julio de1975 Relativa a los Residuos DOCE Nº L 199 de 25 de Julio. Modificada por la Directiva del Consejo 91/156/CEE de fecha 18de marzo de 1991, publicada en el DOCE. N ${ }^{\circ}$ L 78 de 26/03/1991. 
La tipología de evaluación de riesgos para aplicaciones industriales se basa generalmente más en el uso que se hace del método que en el tipo de método empleado. Las ERAI surgen a partir de escenarios específicos, como los delimitados por las emisiones rutinarias o no rutinarias, los suelos contaminados y la eliminación de residuos.

\subsection{Metodología}

\subsubsection{Método NAS}

El método de evaluación de riesgos ambientales diseñado por la National Academy of Sciences (NAS) de Estados Unidos ${ }^{22}$ es un método de evaluación de riesgos para la salud humana (ERS) derivados de productos químicos y excluye los aspectos sociales.

Para evaluar este tipo de riesgos, el método se estructura en cuatro etapas:

1. ${ }^{\text {a }}$ Identificación del riesgo que presenta una determinada sustancia, en función del tipo de perjuicio que puede causar a la salud humana.

2. ${ }^{\text {a }} \quad$ Evaluación de la dosis de respuesta, en función de la relación entre la exposición humana a la sustancia peligrosa y sus efectos.

3. ${ }^{\text {a }}$ Evaluación de la exposición, en función de la cantidad de sustancia que puede alcanzar a una población determinada o la cantidad de población que recibirá la exposición a alguna sustancia previamente determinada.

4. ${ }^{\text {a }}$ Caracterización de los riesgos, en función de la cantidad de daño o perjuicio que puede ocasionar una sustancia, tecnología u otra fuente de riesgo.

Este método presenta serias limitaciones en las evaluaciones de riesgos de emplazamientos específicos y en las evaluaciones de planta/proceso, ya que este tipo de evaluaciones requiere un análisis adicional para examinar las condiciones (cuándo, cómo y por qué) en las que los peligros repercuten ambientalmente.

22 National Academy of Sciences (NAS). Committee on the Institutional Means for Assessment on Risks to public Health (1983): Risk Assessment in the Federal Government: Managing the Process, Washington, NAS. 


\subsubsection{Método de Covello y Merkhofer}

El consenso sobre las fases que debe incluir una ERA se obtiene a partir del método propuesto, en 1993, por Covello y Merkhofer ${ }^{23}$, que realizan una ERA basada en las siguientes fases:

1. $\quad$ Planteamiento del problema. Consiste en delimitar el problema objeto de estudio, considerando la fuente de riesgo que producirá elementos peligrosos (de naturaleza física, química o biológica) y que podrían liberarse al aire, al agua o al suelo.

2. Identificación del peligro. Se trata de conocer los agentes que pueden causar daños al receptor (seres humanos, organismos concretos o ecosistemas). $\mathrm{Su}$ identificación puede requerir la localización de aquellos agentes que podrían producir un daño y, trabajando retroactivamente, identificar cómo podría producirse el daño. Alternativamente, en la evaluación de una instalación o proceso, la identificación de los peligros puede deducirse a partir de un examen de las eventualidades que pueden ocurrir durante el funcionamiento en condiciones normales, seguido de una identificación de las consecuencias derivadas de una desviación respecto a dichas condiciones normales. La identificación de peligros esta íntimamente ligada al resto de las fases de la evaluación de riesgos, por ser este un proceso interactivo. Los procedimientos de identificación de peligros están determinados por la naturaleza de los mismos y comprenden actividades como ensayos toxicológicos, análisis de frecuencia de fallos y accidentes y estudios epidemiológicos.

3. $\quad$ Evaluación de las emisiones. Se trata de examinar el potencial que presenta la fuente del riesgo por introducir agentes contaminantes peligrosos. Dicho examen puede ser meramente descriptivo o bien incluir una cuantificación de la emisión. Para llevar a cabo la evaluación se realiza una descripción de los tipos, cantidades, períodos y posibilidades de emisión de agentes peligrosos, junto con una descripción de las variaciones que dichos agentes pueden experimentar ante diferentes actuaciones o acontecimientos.

${ }^{23}$ Covello y Merkhofer (1993): Risk Assessment Methods Approaches for Assessing Health and Environmental Risks, New York, Plenum, págs. 27-29. 
4. ${ }^{\text {a }} \quad$ Evaluación de la exposición. Consiste en la descripción y cuantificación de las condiciones y las características mas importantes de las exposiciones a agentes peligrosos, producidos o liberados por una fuente de riesgo concreta, e incluye una descripción de la intensidad, frecuencia y duración de la exposición a través de los diferentes medios de exposición, así como un examen de las vías de exposición y la naturaleza de la población expuesta.

5. ${ }^{\text {a }}$ Evaluación de las consecuencias. Se examinan las repercusiones de la emisión o generación de la situación peligrosa para la población específica, seguida de una cuantificación de la relación entre las exposiciones al peligro y sus repercusiones sobre la salud humana y los sistemas ecológicos. Generalmente suelen ser objeto de examen la mortalidad y la morbilidad cuando se evalúan las consecuencias sobre la salud humana, mientras que para los sistemas ecológicos las consecuencias que se examinan son mucho mas variadas. Los datos para la evaluación de las consecuencias suelen estar basados en pruebas de toxicidad y ecotoxicidad, en la epidemiología y en la aplicación de modelos dosis-respuesta.

6. ${ }^{\mathrm{a}} \quad$ Estimación del riesgo. Consiste en combinar los resultados de las evaluaciones de las emisiones, la exposición y las consecuencias, a fin de diseñar medidas para reducir los riesgos para la salud humana y el medio ambiente. Suele incluir diversos cálculos sobre el número de personas que, con el transcurso del tiempo, pueden ver afectada su salud, el daño ecológico y el nivel de incertidumbre que presentan los cálculos realizados.

7. ${ }^{\text {a }}$ Valoración del riesgo. En esta fase, excluida en el método $\mathrm{NAS}^{24}$, se trata de conocer la percepción social del riesgo y como influirá esta percepción en la aceptabilidad de dicho riesgo y en la toma de decisiones. La valoración del riesgo puede tener en cuenta los riesgos percibidos y los beneficios de la aceptación de los mismos e incorporar estos asuntos a la evaluación final.

Como se puede observar, en la Figura 1, la propuesta de Covello y Merkhofer incluye tres etapas mas que el método NAS, dado que el origen de éste último está vinculado a las repercusiones sobre la salud humana de la exposición a determinadas sustancias, si bien, posteriormente, se ha ido adaptando al estudio de las repercusiones de exposiciones similares sobre otras especies.

${ }^{24}$ La legislación de la Unión Europea incluye la valoración del riesgo en la evaluación de los riesgos generados por las sustancias peligrosas. 
FIgURA 1.-Etapas evaluadoras en el método NAS y en el método de Covello y Maerkhofer

\begin{tabular}{|c|c|}
\hline MÉTODO NAS & $\begin{array}{c}\text { MÉTODO DE } \\
\text { COVELLO Y MERKHOFER }\end{array}$ \\
\hline & 1. ${ }^{\mathrm{a}}$ Planteamiento del problema \\
\hline 1. ${ }^{\mathrm{a}}$ Identificación de peligro & 2. ${ }^{a}$ Identificación del peligro \\
\hline 2. ${ }^{a}$ Evaluación de la relación dosis-respuesta & 3. ${ }^{a}$ Evaluación de las emisiones \\
\hline 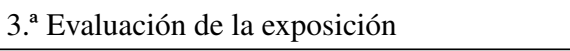 & 4. ${ }^{\text {a }}$ Evaluación de la exposición \\
\hline \multirow[t]{3}{*}{ 4. ${ }^{\mathrm{a}}$ Caracterización de los riesgos } & 5. ${ }^{a}$ Evaluación de las consecuencias \\
\hline & 6. ${ }^{\text {a }}$ Estimación del riesgo \\
\hline & 7. ${ }^{\text {a }}$ Valoración del riesgo \\
\hline
\end{tabular}

Fuente: Elaboración propia.

\subsection{Aplicación a la industria}

En la práctica, la aplicación de los métodos NAS y Covello y Merkhofer a las evaluaciones de riesgos industriales ha dependido del sector industrial objeto de estudio, el tamaño de la empresa, las sustancias utilizadas en los procesos y el tipo de instalaciones industriales.

En Europa, el método de Covello y Merkhofer goza de gran difusión entre la industria, al haber estado impulsado por la aplicación de las Directivas Seveso I, IPPC, y Seveso II. No obstante, la legislación actual no exige a las industrias que lleven a cabo evaluaciones de riesgo para las emisiones industriales producidas en condiciones normales de operación y, por ello, la aplicación de estos métodos es mínima en este tipo de emisiones.

De ahí que seguidamente diferenciemos las aplicaciones en las que dichos métodos presentan una mayor utilidad, las evaluaciones de emisiones industriales en condiciones normales y las evaluaciones en el caso de accidentes y anomalías.

\subsubsection{Evaluación de diversos riesgos ambientales}

Los métodos NAS y Covello y Merkhofer, especialmente este último, presentan una gran utilidad los siguientes casos: 
a) Riesgos del transporte de mercancías

Movilizar un peligro puede generar tanto una disminución como un aumento del riesgo, si se compara con el riesgo derivado del peligro cuando éste se encuentra en un lugar fijo.

Las herramientas con las que se tratan los riesgos del transporte se centran en el recorrido de dicho transporte, pues de su ruta depende el riesgo para la población, cercana o alejada de la ruta, expresando este riesgo como riesgo social de la ruta. Se utiliza el riesgo social debido al potencial de un único accidente para producir daños a un considerable número de personas, realizando comparaciones entre los riesgos derivados de las diferentes rutas y sistemas de transporte ${ }^{25}$.

\section{b) Riesgos financieros}

La inclusión de la evaluación del riesgo ambiental dentro de otros riesgos de la empresa supone adoptar una evaluación integrada de riesgos. La finalidad es conocer la responsabilidad financiera derivada de sucesos no deseados y facilitar la toma de decisiones adecuadas respecto al alcance de las medidas de reducción de riesgos. Para ello, el coste de dichas medidas ha de ser acorde con los costes que pueden generar las responsabilidades en las que la empresa puede incurrir.

Este proceso de evaluación integrada de riesgos se estructura en tres fases:

1. ${ }^{\text {a }}$ Desarrollo del perfil del riesgo. Incluye, además de las fases del método de Covello y Merkhofer, una estimación del coste que puede generar cada situación hipotética de accidente prevista. La frecuencia estimada para el suceso y la información sobre sus consecuencias financieras se combinan a fin de obtener una expresión global del riesgo

2. ${ }^{\text {a }}$ Valoración del control del riesgo. Implica llevar a cabo una evaluación de la eficiencia de las opciones de reducción y control del riesgo a partir de la evaluación de impacto de las medidas de reducción y de la estimación del coste que supondría su puesta en práctica. El riesgo habrá de reducirse hasta el máximo nivel de riesgo que la empresa está dispuesta a asumir.

$3 .^{a}$ Opciones financieras relacionadas con los riesgos. Considera las opciones disponibles para la financiación del riesgo residual, es decir, del riesgo que permanece una vez establecidas las medidas de reducción y control de riesgos.

25 American Institute of Chemical Engineers (1995): Guidelines of Chemical Transportation Risk Analysis, New York, AICI. 
En esta fase la empresa habrá de decidir entre la aceptación de la totalidad del riesgo, la transferencia del riesgo o una combinación de ambas posibilidades.

c) Riesgos derivados de sustancias y productos químicos

La evaluación de este tipo de riesgos atiende a un protocolo claramente definido para alimentos, productos médicos, farmacéuticos y químicos, en los que es necesario reducir al mínimo el riesgo de causar algún daño a sus consumidores. En dicho protocolo, el análisis del ciclo de vida tiene una especial importancia sobre todo en las fases de uso y desecho y como instrumento para el diseño de programas de reducción de riesgos y retirada de sustancias tóxicas del mercado.

El análisis del ciclo de vida es un instrumento de apoyo de la gestión ambiental ${ }^{26}$ que proporciona información sobre los impactos ambientales de productos y servicios en cada una de las etapas de su ciclo de vida y considera todos los tipos de factores ambientales involucrados. El análisis del ciclo de vida trata de garantizar que, al solucionar un problema ambiental, no se genere otro mayor o que, en el peor de los casos, el problema generado, lejos de ser imprevisible, sea el resultado de un proceso integrado de toma de decisiones.

d) Riesgos relativos a la toma de decisiones sobre minimización o reducción de riesgos

Consiste en la evaluación comparativa de los riesgos, asociados a una decisión determinada, a fin de evaluar las diferentes opciones estratégicas de reducción de riesgos. Se utiliza en decisiones como el mantenimiento, reducción o eliminación de la cantidad almacenada de un determinado material o producto, las modificaciones en el diseño o emplazamiento de una instalación, las variaciones en el recorrido del transporte de mercancías o la selección de un medio de transporte determinado.

e) Aplicaciones industriales específicas

Las técnicas desarrolladas para determinados emplazamientos deben particularizarse en atención a su especificidad. En este caso se encuentran las instalaciones marinas, las instalaciones nucleares, la gestión de suelos contaminados, la gestión de residuos y la planificación del uso del suelo en instalaciones industriales peligrosas. Además han de considerarse los riesgos del transporte que, salvo en ámbitos muy específicos del

${ }^{26}$ Fundación Entorno Empresa y Medio Ambiente (1999): Análisis del Ciclo de Vida: Nuevas herramientas para la Gestión Ambiental Empresarial, Madrid, Fundación Entorno, pág. 17. 
transporte terrestre, están excluidos de la cobertura de los seguros de responsabilidad civil ambiental.

\subsubsection{Evaluación de riesgos ambientales por emisiones industriales en condiciones normales}

Los estudios sobre emisiones industriales en condiciones normales se basan en pruebas de toxicidad y ecotoxicidad, realizadas con especies representativas, y en la aplicación de factores de extrapolación o criterios sobre riesgo.

En la práctica, se constata que la prioridad de la industria es cumplir con los límites de contaminación legalmente permitidos. Las consecuencias del incumplimiento de dichos límites son importantes dado que, si se produce un riesgo grave, las autoridades competentes pueden proceder al cierre de las instalaciones, las infracciones ambientales están sancionadas y pueden dar lugar al encarcelamiento de los responsables. Además, el incumplimiento de la legislación en vigor puede conllevar otros efectos negativos, como por ejemplo el incurrir en costes adicionales por volver a solicitar una autorización, la desmotivación de los empleados, unas primas de seguros más elevadas y el posible rechazo por parte de los clientes actuales o potenciales.

Los Registros de Emisiones y Transferencia de Contaminantes (inventarios de emisiones de productos químicos) y el acceso público a una buena parte de la información ambiental de las industrias dan lugar a una mayor presión para que las empresas cumplan con la legislación en vigor.

Algunas empresas elaboran su propio código de conducta ambiental ${ }^{27}$, establecen una mayor exigencia que la legislación en vigor en sus normas internas para emisiones en condiciones operativas normales y adoptan criterios preventivos a fin de reducir las emisiones al mínimo técnicamente posible ${ }^{28}$.

Pero además hay que considerar que gran parte de las empresas estiman que la información sobre incidentes internos, emisiones y vertidos debidos al funcionamiento normal de la planta es confidencial, por lo que este tipo de información es de muy

27 KPMG (2008): KPMG International Survey of Corporate Responsibility Reporting 2008. http://www.kpmg.com/Global/IssuesAndInsights/ArticlesAndPublications/Pages/Sustainabilitycorporate-responsibility-reporting-2008.aspx

28 Recordemos la importancia de las mejores técnicas disponibles (BAT) en el marco legislativo de la Unión Europea. 
difícil acceso ó tan solo está disponible a través de la información que demanda la administración competente en las solicitudes de autorización de emisiones, vertidos, ampliación de instalaciones, etc. Por ello, los resultados de la evaluación de riesgos, por emisiones industriales en condiciones normales, no se suele hacer público en la práctica empresarial.

\subsubsection{Evaluación de riesgos ambientales por accidentes y anomalías}

Tradicionalmente, las técnicas para la evaluación de riesgos ambientales por accidentes y anomalías, desarrolladas para la industria, se han basado en las técnicas de evaluación de riesgos utilizadas en ingeniería para analizar los riesgos de planta o proceso. La evaluación cuantitativa de los riesgos se utiliza, desde hace años, como herramienta altamente fiable en la de toma de decisiones por la industria aerospacial, aeronáutica y nuclear. El interés por el uso de las técnicas de evaluación cuantitativa de riesgos para evaluar la seguridad de las instalaciones industriales ha crecido de forma considerable en Europa ${ }^{29}$ debido al aumento de legislación europea sobre ésta materia ${ }^{30}$.

La evaluación cuantitativa de riesgos se centra en la fiabilidad y en la seguridad de la planta y equipos para los trabajadores, las consecuencias de accidentes mayores en procesos peligrosos y el impacto sobre la salud pública y el medio ambiente. Estas técnicas son muy similares a las técnicas de evaluación de impacto ambiental aplicadas en la planificación de una nueva planta industrial.

Las técnicas para evaluar los riesgos que entrañan las emisiones industriales accidentales para la salud humana están mucho más avanzadas que las que se refieren

29 Pitblado y Turney (1996): Risk Assessment in the Process Industries. Rugby. AICI. P. 97.

${ }^{30}$ Legislación/ Unión Europea: Directiva 82/501/CEE, del Consejo de 24 de junio, relativa a los riesgos de accidentes graves en determinadas actividades industriales DOCE $\mathrm{N}^{\circ} \mathrm{L} 230$ de 5/08/1982 Legislación/ Unión Europea: Directiva 96/61/CE del Consejo, de 24 de Septiembre de 1996, relativa a la prevención y control integrados de la contaminación. DOCE No L257 de 10/10/1996. Legislación/ Unión Europea: Directiva 96/82/CE del Consejo, de 9 de Diciembre de 1996, relativa al control y riegos inherentes a los accidentes graves en los que intervengan sustancias peligrosas. DOCE, N L 10, de 14/01/1997. Legislación/ Unión Europea: Directiva del Consejo 75/442/CEE, de 15 de Julio de1975 Relativa a los Residuos DOCE Nº L 199 de 25 de Julio. Modificada por la Directiva del Consejo 91/156/CEE de fecha 18de marzo de 1991, publicada en el DOCE. $N^{\circ}$ L 78 de 26/03/1991.entre otras. 
a los riesgos ecológicos. Algunas empresas han desarrollado modelos propios para la evaluación de estos riesgos, tanto de carácter cuantitativo como cualitativo, o han adaptado los métodos NAS y Covello y Merkhofer a sus necesidades. Varias compañías han desarrollado técnicas completamente integradas que abarcan todo tipo de riesgos a todos los niveles de producción y consumo ${ }^{31}$.

La evaluación de riesgos ambientales por accidentes y anomalías se basa en la identificación del posible peligro y el hipotético escenario de emisión, el análisis de sus efectos o consecuencias y, cuando es necesario, la estimación cuantitativa de la probabilidad del suceso y su comparación con los criterios previamente acordados, a fin de reducir la posibilidad del suceso o sus consecuencias hasta un nivel satisfactorio. En emplazamientos específicos, esta evaluación se desarrolla en las etapas siguientes ${ }^{32}$ :

1. ${ }^{\circ}$ Identificación del peligro

2. ${ }^{\circ}$ Evaluación de la emisión

3. Evaluación de la exposición

4. ${ }^{\circ}$ Evaluación de las consecuencias

5. ${ }^{\circ}$ Estimación del riesgo

$6^{\circ}$ Alcance de emisiones accidentales

Posiblemente, en el futuro, la industria podrá realizar evaluaciones de riesgos ambientales más completas, pero será necesaria una orientación clara sobre los criterios de aceptabilidad y tolerancia. Aún así, la industria puede, al menos, identificar los posibles peligros ambientales y tomar las medidas pertinentes para minimizar el riesgo de una emisión accidental de sustancias peligrosas. El análisis cuantitativo de la fiabilidad relaciona la fiabilidad que ofrece cada una de las instalaciones y sus componentes con el riesgo ambiental que suponen las emisiones accidentales o rutinarias debidas a fallos en los mismos ${ }^{33}$.

31 Véase su detalle en Fairman y otros (1998): Evaluación del riesgo Medioambiental: Enfoque, Experiencias y Fuentes de Información, Copenhague, AEMA, págs. 92, 96 y 103.

32 Para mayor detalle véase Cabezas Ares (2003): Los Seguros de Responsabilidad Civil Medioambiental en la Industria, León, Servicio de Imprenta. Secretariado de Publicaciones y Medios Audiovisuales, Universidad de León.

33 Imperial College/HMIP (1995): Link Research Project. Pollution Risk Assessment Techniques for Non-Routine Releases from Industrial Processes, Londres, Imperial College/HMIP \& DVD Technica. 


\subsubsection{Evaluación de riesgos versus evaluación de impacto ambiental}

La evaluación de impacto ambiental se define como un proceso jurídico administrativo, cuyo objeto es la identificación, predicción e interpretación de los impactos ambientales que un proyecto o actividad puede ocasionar en caso de ser ejecutado, así como la prevención, corrección y valoración de los mismos, todo ello a fin de ser aceptado, modificado o rechazado por parte de la empresa y las administraciones que deben autorizar la puesta en práctica de dicho proyecto o actividad $^{34}$.

En cambio, según se ha indicado, la evaluación del riesgo ambiental se identifica con la estimación de la posibilidad de desastre, es decir, con la combinación de probabilidad o frecuencia de la aparición de un peligro determinado y la magnitud de las consecuencias de tal aparición ${ }^{35}$.

Los aspectos cualitativos de la evaluación de impacto ambiental reflejan la naturaleza, intensidad, extensión, momento, persistencia, reversibilidad, efecto, acumulación, recuperabilidad, periodicidad, sinergia e importancia de un impacto medioambiental. En cuanto a los aspectos cuantitativos, con la evaluación de impacto ambiental se trata de medir y valorar los diversos impactos, para obtener el impacto ambiental total.

La comparación de la evaluación de impacto ambiental y evaluación de riesgos ambientales permite afirmar que:

- Se puede establecer una similitud entre los conceptos magnitud de las consecuencias, intensidad e impacto. Puesto que riesgo es igual a frecuencia por intensidad, entonces el impacto es una parte del riesgo y, por ello, la evaluación de riesgos ambientales es más amplia que la evaluación de impacto ambiental ya que ésta segunda no toma en consideración la probabilidad o frecuencia.

- Mientras que la evaluación de impacto ambiental se realiza para conocer el grado de adaptación de una actividad al cumplimiento de la legislación en vigor, la evaluación de riesgos ambientales mide el daño esperado como resultado de un evento.

${ }^{34}$ Conesa Fernández-Vítora (1997): Instrumentos de la Gestión Ambiental en la Empresa, Madrid, Mundi-Prensa, pág. 239.

35 Fairman y otros (1998): Evaluación del riesgo Medioambiental: Enfoque, Experiencias y Fuentes de Información, Copenhague, AEMA, pág. 107. 
- La evaluación de riesgos ambientales es dinámica, pues entraña la responsabilidad para la empresa a lo largo del tiempo. En cambio, la evaluación de impacto ambiental es estática, ya que, una vez obtenida la autorización administrativa, cesa el interés de la empresa por este instrumento, de ahí que se le califique como instrumento de gestión ambiental preventivo.

- La metodología usada para la evaluación de impacto ambiental es, generalmente, de gran utilidad en la evaluación de riesgos ambientales.

- Tanto la evaluación de riesgos ambientales como la evaluación de impacto ambiental pueden formar parte de un sistema de gestión ambiental previamente definido.

- La evaluación de impacto ambiental está próxima a la identificación de peligros, ya que trata de predecirlos, identificarlos e interpretarlos, mientras que la evaluación de riesgos ambientales gestiona dichos riesgos una vez evaluados, siendo por tanto más amplia y completa.

\section{LA RELACIÓN ENTRE RIESGO Y NORMALIZACIÓN AMBIENTAL}

Como se ha indicado, los organismos y entidades normalizadoras defienden que la implantación de un sistema de gestión ambiental normalizado (como ISO 14000 o EMAS) da lugar a una reducción del riesgo ambiental en los procesos certificados según dichas normas.

Esta opinión no es compartida por el sector asegurador ${ }^{36}$ al considerar que dos procesos similares, ambos certificados, pero ubicados en lugares diferentes, no siempre presentan un riesgo ambiental similar.

Algunos aseguradores, reconociendo que el primer paso hacia la prevención estriba en que el contaminador potencial sea consciente de los riesgos ambientales que genera, consideran que la implantación de un sistema de gestión ambiental normalizado responde sólo parcialmente a las expectativas depositadas en dicho sistema.

El conocimiento del estado inicial del emplazamiento y de sus impactos ambientales es un paso previo a cualquier aseguramiento. Esta es una de las razones principales

36 Malaval (1999): Développement Durable, Assurances et Environment, París, Económica, págs. 367-383. 
que ha llevado al sector asegurador a tratar el riesgo ambiental de manera diferente a otros riesgos.

La planificación ambiental, de acuerdo con la norma ISO 14001, comienza con un ecodiagnóstico que, para ciertos aseguradores, está próximo, en contenido y objetivos, a los análisis de riesgos previos a la suscripción de pólizas de seguros de responsabilidad civil ambiental.

Para conocer el riesgo asegurado, el asegurador ha de estar informado de la evolución positiva o negativa de dicho riesgo. Generalmente el seguimiento de la evolución de los riesgos se instrumenta en las fichas anuales de renovación, que imponen a las dos partes obligaciones en materia de gestión, ya que en los seguros de responsabilidad civil ambiental no se admite la renovación tácita, lo que obliga a las dos partes a revisar anualmente las condiciones de asegurabilidad del riesgo.

Tanto en el sistema ISO como en el EMAS, es necesario identificar y evaluar periódicamente los impactos ambientales de los procesos certificados. Estos estudios son objeto de una documentación actualizada y suponen una fuente de información de primer orden sobre la evolución de los aspectos ambientales de la empresa, fácilmente asumible por los aseguradores.

Más aún, en el sistema EMAS, la declaración ambiental constituye un proceso documental de información ambiental sobre la situación del emplazamiento y su evolución. Esta declaración ambiental obligatoria ha de hacerse pública, como máximo, cada tres años y ha de estar validada por verificador ambiental independiente. Entre dos publicaciones se realizan declaraciones simplificadas anualmente.

La prevención de los riesgos ambientales es una de las condiciones fundamentales para el asegurador. El plan de prevención no tiene como objeto regular todos los problemas detectados por el análisis de riesgos antes de la suscripción del contrato de seguro de responsabilidad civil ambiental. El objeto de dicho plan de prevención es guiar al asegurado en una gestión coherente de reducción del riesgo y da lugar a como:

- Puesta en marcha de instalaciones de tratamiento

- Barreras destinadas a evitar la propagación de contaminación potencial

- Programas de vigilancia de residuos

- Procedimientos que favorecen un mayor control de los riesgos

Los aseguradores estiman que los sistemas de gestión ambiental forman parte de la prevención de riesgos. Así la trilogía: política, objetivos y programas, contenida tanto 
en ISO como en EMAS, responde, según los aseguradores, a la preocupación por elaborar estrategias preventivas en los emplazamientos industriales ${ }^{37}$.

Por tanto, la implantación de un sistema de gestión ambiental implica la puesta en marcha de una vigilancia regular de los parámetros ambientales más importantes y de las actividades que tienen un posible impacto ambiental.

Los aseguradores admiten que la implantación de un sistema de gestión ambiental pone de manifiesto la voluntad, por parte del asegurado, de tener en cuenta los problemas ambientales, pero también consideran que la disminución posible de los riesgos sólo es real cuando se implantan medidas concretas de prevención.

Para argumentar este análisis, los aseguradores se apoyan en el Anexo A de la norma ISO 14.001 que precisa:

El sistema de gestión medioambiental suministra un proceso estructural con vistas a obtener una mejora continua, a un ritmo y con una importancia que serán determinados por el organismo a la luz del contexto económico y de otras circunstancias. Aunque se pueda esperar una cierta mejora del resultado medioambiental, tras la adopción de esta aproximación sistemática, hay que comprender que el sistema de gestión medioambiental es una herramienta que permite a la empresa alcanzar y dominar sistemáticamente el nivel medioambiental que ha establecido. El establecimiento y el funcionamiento de un sistema de gestión medioambiental llevará consigo necesariamente una reducción inmediata de impactos medioambientales negativos.

Además, los aseguradores tienen en cuenta que la implantación de un sistema de gestión ambiental implica a una organización pero no justifica la calidad de su gestión. Por esta razón distinguen entre los emplazamientos certificados ISO o los lugares registrados EMAS y los lugares con implantación de un sistema de gestión ambiental sin reconocimiento por un tercero. Efectivamente, la certificación ISO 14.001 o el registro EMAS ofrece la posibilidad de obtener el reconocimiento de los esfuerzos comprometidos y por lo tanto la confianza de las partes interesadas. Certificación y registro constituyen una garantía de credibilidad de las informaciones comunicadas y de la realidad de la aplicación de un sistema de gestión ambiental.

37 Malaval (1999): Développement Durable, Assurances et Environment, París, Económica, pág. 371 . 
Para los aseguradores, la realización de ecoauditorías supone un elemento favorable y no determinante para la suscripción del riesgo, que complementa el protocolo de asegurabilidad pero que no sustituye la información requerida por las aseguradoras para fijar sus condiciones.

Para ilustrar las razones de sus dudas, los aseguradores plantean la siguiente paradoja en términos de riesgos ${ }^{38}$. Sean dos fábricas A y B:

- Fábrica A: Contiene un stock de productos peligrosos, está situada en una zona geológica impermeable en pleno campo y no cuenta con ningún sistema de gestión ambiental.

- Fábrica B: su stock de productos peligrosos es similar al de la fábrica A, se ubica próxima a un curso de agua, río arriba de un emplazamiento urbano y ha adoptado un sistema de gestión ambiental.

Bajo estas condiciones, desde el punto de vista asegurador, la fábrica B, incluso certificada, presenta más riesgo que la fábrica $\mathrm{A}$.

El seguro de responsabilidad civil ambiental es un producto reciente y, por el momento, los aseguradores no han establecido una relación entre los elementos de la ecoauditoría y el nivel de riesgo, siendo la utilización de la experiencia aún muy débil. Para mantener su posición las aseguradoras efectúan un paralelismo entre la gestión ambiental y la gestión de la calidad, señalando que no se han establecido nunca relaciones entre los sistemas de gestión de la calidad y una disminución objetiva del riesgo de responsabilidad civil.

La formula escogida por las compañías de seguros consiste en medir, con una adecuada fiabilidad, el riesgo en un momento dado y en proporcionar una seguridad técnica en cuanto al conocimiento del riesgo, practicando auditorias o diagnósticos de emplazamientos antes de la suscripción o de la modificación de cualquier póliza de seguro de responsabilidad civil ambiental ${ }^{39}$.

Por todo ello, los aseguradores elaboran sus propios métodos de análisis. Entre los aseguradores existe la convicción de que aquel que haya concebido el método más eficiente para suscribir los riesgos presentados se beneficiará de una fuerte ventaja

${ }^{38}$ Malaval (1999): Développement Durable, Assurances et Environment, Paris, Económica, pág. 369.

39 En el caso del Pool Español de Riesgos ambientales se denominan inspecciones de riesgos y se estudian posteriormente. 
competitiva. Así, al evaluar correctamente los riesgos ambientales, condicionar la garantía a medidas de prevención eficaces y proponer las primas en relación al nivel de riesgos, los suscriptores de un seguro de responsabilidad civil ambiental participan en el enriquecimiento de su empresa, de forma similar a lo que ocurre en el caso de riesgos bien conocidos por las aseguradoras, como por ejemplo en los ramos de incendios o del automóvil.

La falta de unanimidad sobre el método más idóneo para analizar el riesgo ambiental ha llevado a los organismos de normalización a estudiar dicho métodos. El Comité Técnico AEN/CTN 150 de AENOR ha elaborado la Norma UNE 150.00840 sobre análisis y evaluación del riesgo medioambiental. La aprobación de dicha norma estaba inicialmente prevista a lo largo de 1999, pero se retrasó hasta el primer semestre de 2000, tras someterla el Ministerio de Industria y Energía a información pública ${ }^{41}$, habiendo sido revisada y actualizada en marzo del $2008^{42}$.

La elaboración de la norma UNE 150.008 tiene en cuenta que los intermediarios financieros, las compañías de seguros, las administraciones públicas y otras organizaciones vienen realizando análisis y evaluaciones de los riesgos ambientales y pretende disponer de una metodología común, de forma que los resultados de estos análisis y evaluaciones se puedan utilizar para la toma de decisiones diversas.

En la elaboración de esta norma, para la versión del año 2000, AENOR ha tomado como guía El Libro verde sobre la reparación del Daño ecológico (de las Comunidades Europeas), el borrador del anteproyecto español de Ley de Responsabilidad Civil derivada de la actividades con incidencia ambiental y, sobre todo, la norma británica BS 8444 de gestión de riesgo ambiental, la norma australiana y neozelandesa 4360 de gestión de riesgo ambiental, así como un informe japonés sobre riesgo ambiental.

La diferente legislación promulgada por la Unión Europea entre el año 2000 y el 2008, ha hecho conveniente la revisión de la norma UNE 150.008:2000 EX, adaptándola a todas ellas junto con las diversas iniciativas legislativas nacionales, que afectan

${ }^{40}$ Fundación Entorno Empresa y Medio Ambiente (1999): El Riesgo Medioambiental en la Industria. Madrid. Fundación Entorno. págs.35-39

${ }^{41}$ Legislación/ España: Resolución de 16 de marzo de 2000, de la Dirección General de Industria y Tecnología, por la que se modifica la de 29 de Septiembre de 1999, por la que se someten a información pública los proyectos de normas UNE que AENOR tiene en tramitación, correspondientes al mes de agosto de 1999. BOE No 77, de 30/03/2000.

42 AENOR (2008): UNE 150.008 Análisis y Evaluación del Riesgo Medioambiental. Madrid. AENOR. 
al riesgo ambiental, tanto desde la perspectiva del análisis, como desde la perspectiva de su evaluación e incluso de su gestión.

Uno de los temas cruciales de discusión en la elaboración de la norma UNE 150.008 ha sido su aplicabilidad y comparación con las normas ISO de las series $14.000 \mathrm{y}$ 19.000. Cuando se implanta un adecuado sistema de gestión ambiental, la empresa confía en que su gestión sea ambientalmente correcta y disminuyan sus riesgos ambientales, porque:

1. Ha analizado todos sus aspectos ambientales significativos

2. Ha identificado y cumple la legislación ambiental en vigor que le es aplicable

3. Ha puesto en marcha un proceso de mejora continua, entre cuyos efectos se encuentra una reducción de su riesgo ambiental hasta el nivel de riesgo aceptable

Para establecer este sistema de gestión ambiental, la empresa habrá empezado por recoger e investigar los datos proporcionados por la evolución de sus variables ambientales claves. Seguidamente habrá realizado un ecodiagnóstico de su situación y, en su caso, habrá decidido acudir a la norma ISO 14.001, certificarse y demostrar que ha disminuido su riesgo ambiental. Pero además, la empresa obtendría otros beneficios económicos, de imagen, etc.

El objetivo de la norma UNE 150.008 es establecer criterios de identificación, análisis, evaluación y, en su caso, certificación del riesgo ambiental de una organización, independientemente de su tamaño y de su actividad, teniendo en cuenta tanto sus actividades actuales como sus actividades pasadas y con independencia de que tenga implantado o no el sistema ISO 14.001.

Para alcanzar dicho objetivo, la norma UNE $150.008^{43}$ propone una metodología que aborda el análisis de riesgos ambientales de forma completa y se divide en las siguientes fases:

- Identificación de causas y peligros,

- Identificación de sucesos iniciadores,

- Asignación de probabilidad al suceso iniciador,

- Postulación de escenarios del accidente,

43 AENOR (2008): UNE 150.008 Análisis y Evaluación del Riesgo Medioambiental. Madrid. AENOR. 
- Asignación de probabilidad del escenario de accidente,

- Estimación de las consecuencias asociadas al escenario de accidente,

- Estimación del riesgo.

Estas fases se representan en el proceso iterativo que se describe en la figura 2.

Figura 2.-Análisis del riesgo

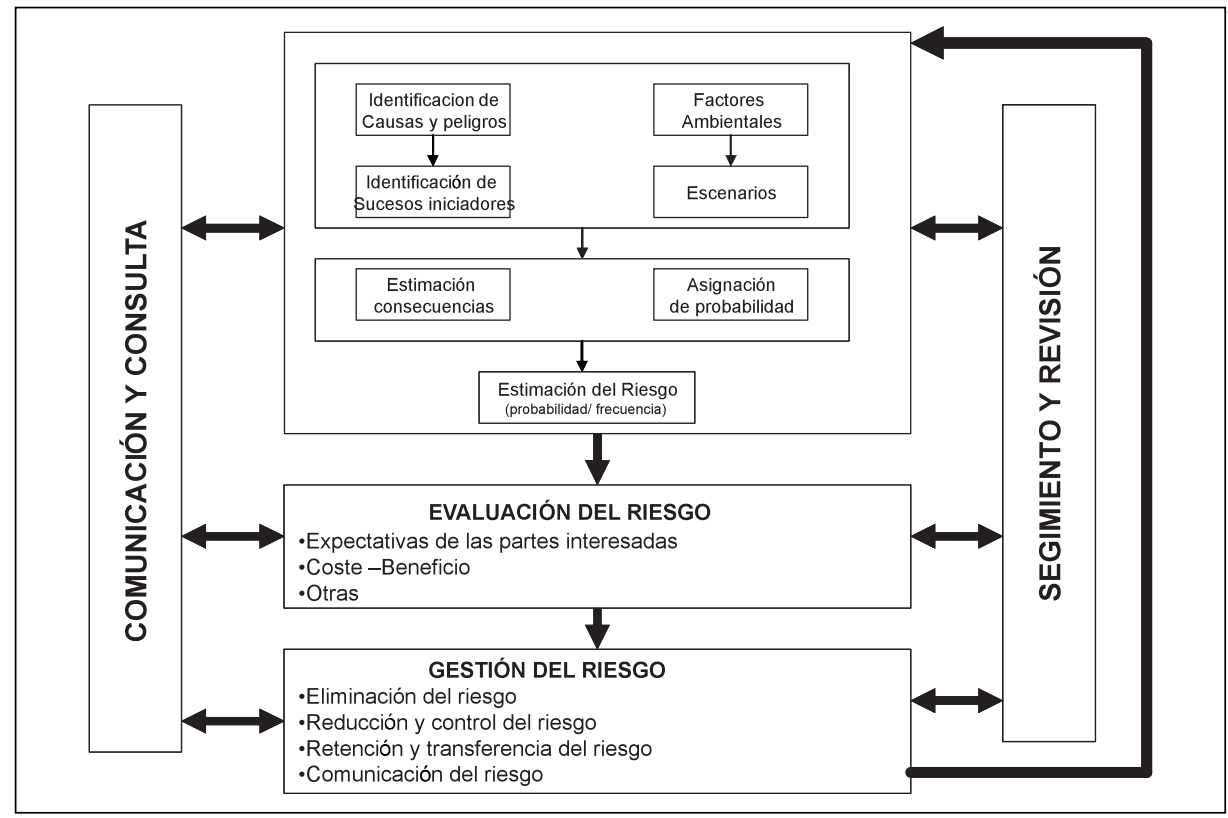

Fuente: AENOR Norma UNE 150.008:2008.

Para identificar los peligros, la norma UNE 150.008 parte del diagnostico de las fuentes potenciales de peligro (materias primas, productos, residuos, almacenamientos, procesos, gestión de instalaciones y actividades desarrolladas) y del estudio de los sucesos indicadores de accidente, analizando seguidamente las medidas que pueden adoptarse a fin de prevenir o mitigar los efectos y realizar un diagnóstico de los peligros derivados de la localización de la instalación y de la acción del entorno sobre la instalación.

La estimación del riesgo ambiental, de acuerdo con la norma UNE 150.008, se realiza a partir del diseño de los escenarios en los que puede ocurrir el suceso y la estimación de la probabilidad de ocurrencia, en cada escenario, de dicho suceso, así como 
de las posibles consecuencias sobre el entorno natural, el entorno humano y el entorno socioeconómico.

Con la aprobación de la UNE 150.008:2008, las entidades financieras, las compañías de seguros, las administraciones públicas y otras instituciones, pueden aplicar prácticas normalizadas para identificar, analizar y evaluar los riesgos ambientales de las organizaciones, así como las responsabilidades que pudieran derivarse y, de esta forma, tener un mayor conocimiento ante decisiones como por ejemplo la concesión de créditos y préstamos o la fijación de condiciones de asegurabilidad.

Así por ejemplo los aseguradores de riesgos medioambientales basan sus decisiones (aceptación o no del riesgo y fijación en su caso de condiciones de cobertura específicas) en un análisis individualizado de los factores y circunstancias que influyen en la gravedad de los riesgos analizados.

Por otra parte, todas las Administraciones Públicas con competencias en la concesión de autorizaciones en materia de medio ambiente, realizan, con mayor o menor profundidad y con un sistema más o menos homogéneo, algún tipo de comprobación de las características y las condiciones de prevención de determinadas actividades industriales que se consideran potencialmente contaminantes, constituyendo éste uno de los elementos necesarios para la toma de decisiones en cuanto a su autorización administrativa.

Esta tarea se lleva a cabo mediante la inspección de la instalación, el análisis de la información pertinente o ambas.

Según el Pool Español de Riesgos Medioambientales ${ }^{44}$, con la entrada en vigor del Reglamento de la Ley de Prevención y Control Integrados de la Contaminación ${ }^{45}$, el análisis de riesgos es obligatorio para las instalaciones industriales reguladas por dicha ley y ha de hacerse de forma integrada y sistemática.

Por último, la Ley de Responsabilidad Medioambiental ${ }^{46}$ extiende esta obligación a todas las actividades comprendidas en su Anexo III y establece la obligación de reglamentar su contenido.

44 www.perm.es

45 Legislación/ España: Real Decreto 509/2007, de 20 de abril, por el que se aprueba el reglamento para el desarrollo y ejecución de la Ley 16/2002, de 1 de julio, de prevención y control integrado de la contaminación. BOE No 96 21/04/2007

46 Legislación/ España: Ley 26/2007, de 23 de octubre, de Responsabilidad Medioambiental. BOE N 255 24/10/2007. 
En beneficio tanto de las entidades privadas como de las Administraciones públicas, se ha desarrollado el sistema de evaluación de la norma UNE 150008-EX, mediante el que se pretende suministrar la información necesaria para lograr que las labores de control de riesgos medioambientales sean compatibles con un sistema de evaluación unificado, asumible por todas las entidades antes citadas.

En este ámbito, la Evaluación del riesgo medioambiental tiene como objeto principal identificar los peligros de generar o sufrir un accidente que cause contaminación y evaluar los riesgos consecuentes y las medidas implantadas para evitar su ocurrencia o minimizar sus consecuencias y como objetivo complementario, proponer las mejoras pertinentes para la reducción de los riesgos evaluados.

\section{NORMALIZACIÓN Y COBERTURA POR EL SECTOR ASEGURADOR}

Como reiteradamente se ha expuesto, la industria es uno de los mayores contaminantes potenciales, si bien sus episodios mas conocidos son los accidentes de gran magnitud, con exposiciones al riesgo potencial de gran intensidad, durante un corto período de tiempo y que, generalmente, tienen una repercusión considerable en los medios de comunicación social.

Además de estos accidentes, deberían tenerse en cuenta otros episodios de menor magnitud y con un largo período de exposición. Sin embargo, la disponibilidad de información sobre estos incidentes es prácticamente nula, dado que las empresas suelen considerar totalmente confidencial esta información. Por ello, no existen bases de datos ni informaciones fiables sobre los incidentes industriales ocurridos y sus consecuencias ambientales.

\subsection{Unidad de estudio}

En artículo 2 del antiguo Reglamento $\mathrm{EMAS}^{47}$ se denominaba actividad industrial a toda actividad recogida en las secciones $C$ y $D$ de la clasificación de actividades

47 Legislación/ Unión Europea: Reglamento 1836/93 del Consejo, de 29 de junio de 1993, por el que se permite que las empresas del sector industrial se adhieran con carácter voluntario a un sistema comunitario de gestión y auditoria medioambientales (EMAS). DOCE L N ${ }^{\circ} 168$, de 10/07/1993. Esta definición se sustituye en el nuevo Reglamento EMAS por la de organización. Así, en su artículo 2, el nuevo Reglamento EMAS define organización como la compañía, 
económicas en las Comunidades Europeas ${ }^{48}$ mas las actividades relacionadas con la producción de electricidad, gas, vapor y agua caliente, o con el reciclado, tratamiento, destrucción o eliminación de residuos sólidos o líquidos.

La Directiva IPPC ${ }^{49}$ define instalación como la unidad técnica fija en la que se lleven a cabo determinadas actividades relacionadas con el ámbito de aplicación de la presente Directiva.

Por otro lado la Directiva Seveso II $^{50}$ realiza las siguientes definiciones en relación con la unidad de estudio:

- Establecimiento: la totalidad de la zona bajo en control de un industrial en la que se encuentren sustancias peligrosas en una o varias instalaciones, incluidas las infraestructuras o actividades comunes o conexas.

- Instalación: es una unidad técnica, situada en el interior de un establecimiento, en la que se produzcan, utilicen, manipulen, o almacenen sustancias peligrosas. Incluye todos los equipos, estructuras, canalizaciones, maquinaria, instrumentos, ramales ferroviarios particulares, dársenas, espigones, depósitos o estructuras similares, estén a flote o no, necesarios para el funcionamiento de la instalación.

- Industrial: cualquier persona física o jurídica que explote o posea el establecimiento o la instalación o, si esta previsto en la legislación nacional, cualquier

sociedad, firma, empresa, autoridad o institución, o parte o combinación de ellas, tenga o no personalidad jurídica, sea pública o privada, que tiene sus propias funciones y administración. Legislación/ Unión Europea: Reglamento 761/2001 del Parlamento Europeo y del Consejo, de 19 de marzo de 2001, por el que se permite que las organizaciones se adhieran con carácter voluntario a un sistema comunitario de gestión y auditoria medioambientales (EMAS). DOCE L $\mathrm{N}^{\circ} 114$, de 24/04/2001.

48 Legislación/ Unión Europea: Reglamento $3037 / 90$ del Consejo, de 9 de Octubre de 1990, relativo a la nomenclatura estadística de actividades económicas en la Comunidad Europea. DOCE L N ${ }^{\circ} 293$, de 24/10/1990.

49 Legislación/ Unión Europea: Directiva 96/61/CE del Consejo, de 24 de Septiembre de 1996, relativa a la prevención y control integrados de la contaminación. DOCE L No 257, de 10/10/1996.

${ }^{50}$ Artículo 2. Legislación/ Unión Europea: Directiva 96/82/CE del Consejo, de 9 de Diciembre de 1996, relativa al control y riesgos inherentes a los accidentes graves en los que intervengan sustancias peligrosas. DOCE L No 10, de 14/01/1997. 
persona en la que haya delegado, en relación con el funcionamiento técnico, un poder económico determinante.

Una empresa industrial puede poseer varias plantas o centros productivos, localizados en diferentes puntos geográficos. La unidad de estudio a considerar es cada uno de estos centros geográficamente separados y que constituyen una unidad de emplazamiento identificable y separada del resto de las instalaciones técnicas productivas de dicha empresa.

\subsection{Sucesos en estudio}

Los sucesos a estudiar en cada instalación industrial son los siguientes:

- Accidente mayor, definido como un suceso inesperado y súbito, resultante de acontecimientos anormales, durante una actividad industrial, que suponen un peligro grave para los trabajadores, la población o el medio ambiente, sea inminente o no, dentro o fuera de las instalaciones y en el que intervienen una o mas sustancias peligrosas ${ }^{51}$.

- Accidente grave, definido como un hecho, emisión, incendio o explosión importantes, que resulte de un proceso no controlado, debido al funcionamiento de un establecimiento industrial, que suponga un peligro grave, inmediato o diferido, dentro o fuera del establecimiento, para la salud humana o el medio ambiente y en el que intervengan una o varias sustancias peligrosas ${ }^{52}$.

Estas dos definiciones son similares en lo relativo a las consecuencias de los accidentes, difiriendo sólo en la identificación del origen de dichos accidentes. Los accidentes mayores tienen su origen en un suceso anormal, mientras que los accidentes graves se originan por un proceso no controlado. No obstante ambos tipos de accidentes son sucesos de origen industrial y con repercusiones de gran magnitud.

51 Organización Internacional del Trabajo (OIT) (1991): Prevención de Accidentes Industriales Mayores. Ginebra. OIT P. 3.

52 Artículo 4.5 de Legislación/ Unión Europea: Directiva 96/82/CE del Consejo, de 9 de Diciembre de 1996, relativa al control y riesgos inherentes a los accidentes graves en los que intervengan sustancias peligrosas. DOCE L No 10, de 14/01/1997. 


\subsection{Actividades y sustancias peligrosas}

En la Unión Europea, los índices de peligrosidad industriales atienden al tipo de actividad y las sustancias procesadas por la industria, según se indica en la Figura 3. La legislación de la EPA estadounidense ${ }^{53}$ opta por clasificar los riesgos ambientales de la industria en función de las sustancias manejadas, presentado un listado de 584 sustancias diferentes.

FIgURA 3.-Unión Europea. Criterios de clasificación de riesgo ambiental en la industria

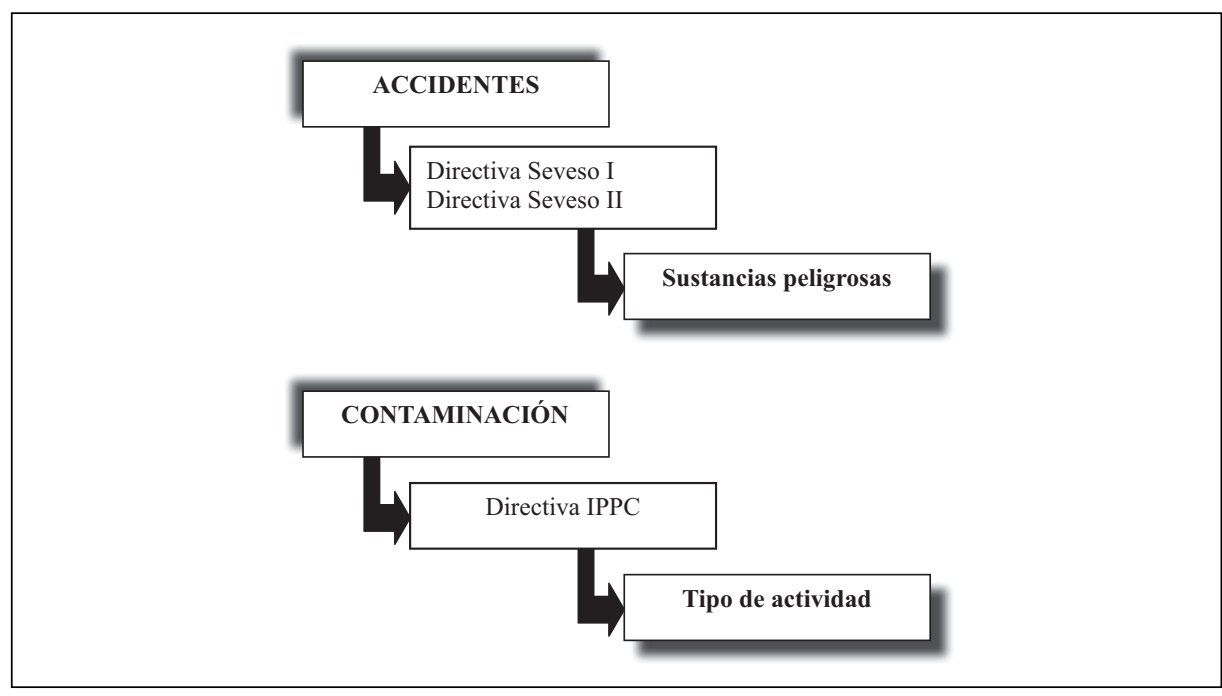

Fuente: Elaboración propia.

Para la estimación del riesgo ambiental potencial de las instalaciones industriales, la Directiva IPPC adopta como criterio el tipo de actividad que en ellas se realiza ${ }^{54}$. En cambio el criterio seleccionado por las Directivas Seveso I y Seveso II para la estimación de este riesgo es las sustancias peligrosas, sus mezclas o preparados, es-

$53<$ http://www.epa.gov>

54 Véase Legislación/ España: Ley 16/2002, de 1 de julio, de Prevención y Control Integrado de la Contaminación. BOE No 157 02/07/2002. 
tableciendo un listado de este tipo de sustancias ${ }^{55}$, fijando sus umbrales máximos de admisibilidad y, en el caso de la Directiva Seveso II, contemplando su almacenamiento (hasta entonces el almacenamiento no se había considerado).

Por otra parte, la Directiva Seveso II $^{56}$ excluye de su ámbito de aplicación las actividades siguientes, dado que cuentan con una legislación específica:

- Las desarrolladas en instalaciones militares

- Los peligros nucleares

- El transporte de sustancias peligrosas por carretera, ferrocarril, vía navegable interior, marítima o aérea.

- El transporte de sustancias peligrosas por canalizaciones que se encuentran fuera de los establecimientos.

- Las realizadas en vertederos de residuos.

Existe una gran coincidencia entre las actividades excluidas del ámbito de aplicación de la Directiva Seveso II y las actividades que las aseguradoras han decidido excluir del seguro de responsabilidad civil ambiental, pues además de las citadas anteriormente (excepto el transporte por carretera de sustancias peligrosas bajo el control del explotador, que se puede contratar como cobertura adicional), las aseguradoras han decidido no suscribir pólizas de este tipo de seguro en las actividades relacionadas con prospecciones en plataformas marinas, mientras que, en el caso de los vertederos, las suscribirá solamente cuando estén controlados y no clausurados

Además, la Directiva Seveso II incluye expresamente una lista de 30 sustancias o grupos de sustancias con sus valores umbrales, trata al resto de las sustancias químicas en función de su toxicidad, comburencia ó inflamabilidad y fija índices de riesgo para las sustancias tóxicas en función de sus posibles efectos sobre los organismos acuáticos, las reacciones que puedan provocar con el agua o la liberación de gases tóxicos.

La legislación española ${ }^{57}$ incluye una lista de 178 sustancias con sus correspondientes cantidades límites de manipulación. Este listado de sustancias es una transposición

55 Véase Anexo 3

56 Artículo 4.

${ }^{57}$ Legislación/ España: Real Decreto 886/1988, de 15 de junio, sobre prevención de accidentes mayores en determinadas actividades industriales. BOE $\mathrm{N}^{\circ} 187$ de 5/08/1.988., hoy derogado y sustituido por Legislación/ España: Real Decreto 1254/1999, de 16 de julio, por el que se aprueban medidas de control de los riesgos inherentes a los accidentes graves en los que intervengan 
de la Directiva Seveso I y, por tanto, se basa en una lista de sustancias potencialmente peligrosas utilizadas por la industria, aunque también se enumeran algunas actividades que utilizan las mencionadas sustancias.

La Directiva Seveso II aumenta las obligaciones, ya que antes las instalaciones de menor categoría estaban únicamente sujetas a obligaciones muy generales. Entre las nuevas obligaciones destacan:

1. La elaboración de políticas de prevención de accidentes graves.

2. La evaluación de los principales escenarios de posibles accidentes.

3. El establecimiento de planes de emergencia.

4. La divulgación de información al público en general.

Además, la Directiva Seveso II pone mayor énfasis en los sistemas de gestión de la seguridad, a partir de la experiencia adquirida con los últimos accidentes graves, ya que de los setenta accidentes graves ocurridos, que entre 1982 y 1990, un $95 \%$ de ellos podrían haberse evitado aplicando los conocimientos existentes y unos procedimientos adecuados de gestión y explotación ${ }^{58}$.

Según la Organización Internacional del Trabajo ${ }^{59}$, el criterio de determinación del riesgo potencial debe basarse en las cantidades límite establecidas para una lista de sustancias peligrosas. Este criterio también es asumido por la $\mathrm{OCDE}^{60}$ y coincide plenamente con el de la Directiva Seveso I ${ }^{61}$.

sustancias peligrosas. BOE $N^{\circ} 172$ de 20/07/1999, modificado a su vez por Legislación/ España: Real Decreto 119/2005, de 4 de febrero por el que se aprueban medidas e control de los riesgos inherentes a los accidentes graves en los que intervengan sustancias peligrosas, BOE $\mathrm{N}^{\mathrm{o}} 36$ de 11/02/2005y por Legislación/ España: Real Decreto 948/2005, de 29 de julio por el que se aprueban medidas e control de los riesgos inherentes a los accidentes graves en los que intervengan sustancias peligrosas, BOE $\mathrm{N}^{\circ} 181$ de 30/07/2005

${ }^{58}$ Instituto de Investigaciones Ecológicas (1997): Consultoría y Verificación Medioambiental. Málaga. Centauro. V. 5. P. 143.

59 Otganización Internacional del Trabajo (1991): Prevención de Accidentes Industriales Mayores. Ginebra OIT. págs. 2 y 9.

60 OCDE (1992): Principios guías para la prevención de accidentes químicos, preparación y respuesta. Monografía Medioambiental. N. 51. París. OCDE. P. 14.

${ }^{61}$ Esta Directiva ya ha sido transpuesta al ordenamiento español. Legislación/ España: Real Decreto 886/1988, de 15 de junio, sobre prevención de accidentes mayores en determinadas actividades industriales. BOE $\mathrm{N}^{\circ} 187$ de 5/08/1.988., hoy derogado y sustituido por Legislación/ 
Según se acaba de indicar, la Directiva Seveso II defiende criterios mas genéricos pues, desde un punto de vista práctico, se ha comprobado la intervención en accidentes mayores de sustancias no incluidas en el listado de la Directiva Seveso ${ }^{62}$.

\section{MEDIA Y PERCEPCIÓN DEL RIESGO SOCIAL}

\subsection{Indicadores del riesgo}

Los indicadores, que permiten cuantificar de forma breve y sintética el riesgo para la salud humana de una determinada actividad industrial, mas utilizados son la tasa de accidentes mortales y la frecuencia de accidentes mortales ${ }^{63}$.

a) Para una actividad determinada, la tasa de accidentes mortales se define como el número de accidentes mortales, después de 100 millones de horas por persona, de una determinada actividad. Esta tasa equivale aproximadamente al número de horas, por persona, trabajadas por un grupo de 1000 personas en su vida laboral, e incluye únicamente los accidentes con consecuencias inmediatas y no las muertes por enfermedad.

b) Para una actividad determinada, la frecuencia de accidentes mortales se expresa en muertos por persona y año.

España: Real Decreto 1254/1999, de 16 de julio, por el que se aprueban medidas de control de los riesgos inherentes a los accidentes graves en los que intervengan sustancias peligrosas. BOE № 172 de 20/07/1999, modificado a su vez por Legislación/ España: Real Decreto 119/2005, de 4 de febrero por el que se aprueban medidas e control de los riesgos inherentes a los accidentes graves en los que intervengan sustancias peligrosas, $\mathrm{BOE} \mathrm{N}^{\circ} 36$ de 11/02/2005y por Legislación/ España: Real Decreto 948/2005, de 29 de julio por el que se aprueban medidas e control de los riesgos inherentes a los accidentes graves en los que intervengan sustancias peligrosas, $\mathrm{BOE} \mathrm{N}^{\circ}$ 181 de 30/07/2005

${ }^{62}$ Legislación/ Unión Europea: Directiva 82/501/CEE del Consejo, de 24 de junio, relativa a los riesgos de accidentes graves en determinadas actividades industriales. DOCE L N 230 , de 5/08/1982.

${ }^{63}$ Instituto de Investigaciones Ecológicas (1997): Consultoría y Verificación Medioambiental. Málaga. Centauro. Pp.112 y 113 
Así por ejemplo, la tasa de accidentes mortales en la industria química en el Reino Unido $^{64}$ se estima en 4 , por tanto su frecuencia es de $1 \times 10^{-4}$ muertos por persona y año. Ello significa que por cada 10.000 operarios que trabajan en la industria química muere uno por año, o lo que es lo mismo, si una persona trabaja toda su vida laboral en una industria química de 1.000 operarios, durante ese tiempo 4 compañeros suyos fallecerán por accidente laboral.

Para comprender mejor la significación estos indicadores de riesgo para la salud humana es conveniente compararlos con sus equivalentes en otras actividades. En el ejemplo anterior, el riesgo de accidentes mortales en la industria química del Reino Unido es menor que el riesgo generado por actividades como la construcción, la industria pesquera, la minería, la agricultura o la industria mecánica, y mayor que el correspondiente a actividades como la industria maderera, la industria del automóvil o la industria de la confección ${ }^{65}$.

\subsection{Criterios de riesgo social. La experiencia de los Países Bajos}

Los límites del riesgo social constituyen una herramienta útil para establecer criterios de aceptabilidad en actividades peligrosas para la sociedad en su conjunto. En ellos se tiene en cuenta que, en una instalación industrial determinada, pueden producirse varias clases de accidentes, cada uno con una probabilidad de ocurrencia y una gama de posibles efectos sobre la población circundante. Como en cualquier suceso peligroso, puede tolerarse una mayor probabilidad de ocurrencia en aquellos sucesos con menor repercusión, de modo que, al agravarse las consecuencias, la frecuencia de ocurrencia considerada aceptable ha de reducirse.

Cuantificados con estos criterios, la Figura 4 muestra los límites de riesgo social adoptados en los Países Bajos ${ }^{66}$. En función de estos límites, la probabilidad de que un

${ }^{64}$ Casal (1991): La Evaluación del riesgo en la industria química. Jornadas sobre impacto ambiental en la Industria Química. El Escorial, Madrid. Agosto de 1991

${ }^{65}$ Instituto de Investigaciones Ecológicas (1997): Consultoría y Verificación Medioambiental. Málaga. Centauro. P.113

66 Vrom (1990): Premises for Risk management, risk limits in the context of environmental policy. In: Environmental Policy Plan «Keizen of Verliezen» (Second Chamber of the States General, 1988-89 session, 211137). The Hague. The Netherlands, Ministry Of Housing, Physical Planning and Environment. 
accidente de lugar a diez fallecimientos no debe superar el 1 por cada 100.000 años, es decir $10^{-5}$ por año Una frecuencia mayor es inaceptable. Una frecuencia menor o igual a 1 por cada 10.000 .000 años se considera insignificante. Una repercusión $n$ veces mayor debe corresponder a una probabilidad $n$ veces menor que la probabilidad de ocurrencia elevada al cuadrado. Por tanto, la frecuencia máxima permisible de 1.000 muertes, es de $10^{-9}$ por año, mientras que una frecuencia menor o igual a $10^{-11}$ se considera insignificante.

Las frecuencias situadas entre esos valores deben dar lugar a una investigación sobre las posibilidades de reducirla. Esa zona intermedia, para los Países Bajos situada entre $10^{-5}$ y $10^{-7}$, es un margen que permite incluir las incertidumbres asociadas con las evaluaciones de riesgo, las consecuencias de la exposición acumulada y la distinción adecuada de los niveles de aceptabilidad e inaceptabilidad.

Figura 4.—Límites de riesgo social adoptados en los Países Bajos

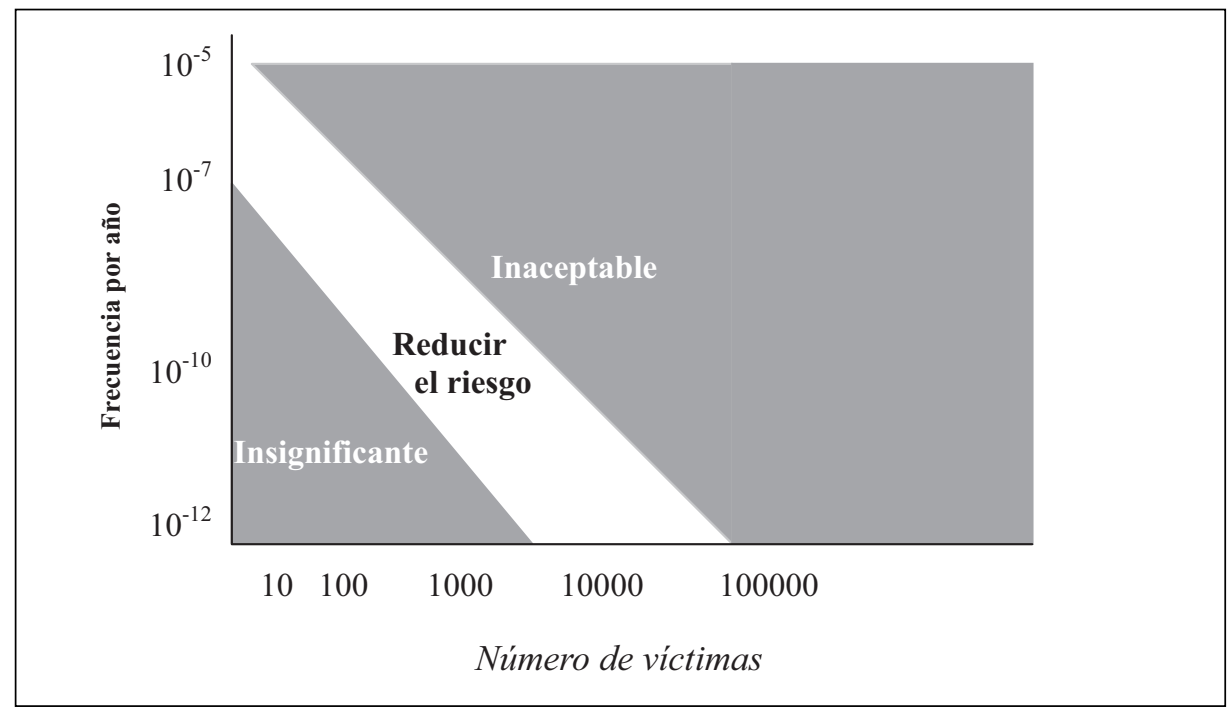

Fuente: Pietersen (1990): Technical Tools for Risk Assessment. Seminario la Prevención de Accidentes Mayores en la Industria, Madrid 11-13 de Septiembre. Ciemat. P. 9 


\subsection{Percepción subjetiva del riesgo}

La fijación de objetivos de riesgo implica tres etapas:

1. Determinar el nivel aceptable de riesgo individual

2. Determinar la aceptabilidad de accidentes que afectan a un gran número de personas (riesgo social), teniendo en cuenta la aversión a los accidentes de gran escala y/o destructivos

3. Determinar la viabilidad de los criterios de aceptabilidad del riesgo

Los riesgos reales de diferentes actividades pueden estimarse en términos cuantitativos mediante una serie de técnicas objetivas. En cambio, la fijación de criterios apropiados de riesgo aceptable o inaceptable se basa en juicios de valor que generalmente dependen de:

- El carácter voluntario o involuntario del riesgo

- La percepción sobre el control que el individuo puede ejercer sobre dicho riesgo

- Los beneficios esperados de la actividad en cuestión

- La naturaleza y frecuencia de los posibles efectos perjudiciales

Dada la subjetividad de la percepción individual del riesgo y la dificultad que plantea su conocimiento, la percepción del riesgo por parte de la sociedad no tiene alcance suficiente para utilizarse como criterio único en la fijación de niveles aceptables de riesgo y, por ello, los poderes públicos establecen estos niveles a partir de la consideración de factores como la repercusión económica directa e indirecta sobre el empleo local, la confianza de los inversores en la actividad, la viabilidad de diversos criterios de riesgo, etc. No obstante, generalmente todo ello suele dar lugar a un proceso negociador en el que se pretende, por cada partícipe en dicho proceso, alcanzar un compromiso social y económico.

Por ejemplo, el gobierno holandés ha establecido como un nivel inaceptable de riesgo colectivo el 1 por 2.000 millones al año por cada 1000 muertes, mientras que el límite en Hong Kong es 1 por 2 millones al año, debido quizá a su mayor densidad de población. 
Para Malaval ${ }^{67}$, el público evalúa los riesgos según tres tipos de criterios: la atrocidad de un siniestro (efectos producidos, inocencia de las víctimas, etc.), la comprensión que dicho público tiene de este riesgo y el número de individuos expuestos. De ahí que la percepción de los riesgos por las poblaciones afectadas varíe a lo largo del tiempo y que dependa de valores éticos, individuales y sociales. Por ello, de nuevo ha de destacarse la importancia de la comunicación del riesgo dentro del análisis y gestión de riesgos

Pero además, mientras que una gran parte de los accidentes industriales y sus riesgos no están socialmente aceptados, existen otros riesgos que si acepta nuestra sociedad, como por ejemplo los riesgos derivados de la circulación terrestre o de la navegación aérea, aunque, en algunos países, cuentan con una frecuencia de accidentes mortales mucho mayor que los accidentes industriales.

\section{ANÁLISIS DE DATOS HISTÓRICOS SOBRE ACCIDENTES INDUSTRIALES}

Existe la posibilidad de consultar alguna de las siguientes bases de batos, que recogen los accidentes industriales relacionados con la utilización de sustancias peligrosas:

- Base de datos MARS: Mayor Accident Reporting System, puesto en marcha por el Joint Reserch Centre. Major Accident Hazards Bureau, para la Comisión Europea (http://mahbsrv.jrc.it). En esta base se van recopilando los informes aportados por los estados miembros sobre accidentes acaecidos en su territorio

- Base de datos SPIRS: Seveso Plants Information Retrieval System, puesto en marcha por el Joint Reserch Centre. Major Accident Hazards Bureau, para la Comisión Europea (http://mahbsrv.jrc.it), en el que se representa un mapa de los accidentes acaecidos en Europa.

- Base de datos FACTS: Failure and Accidents Technical Information Sistema. Esta base de datos esta elaborada por TNO en Holanda.

- Base de datos «The Accidente Database», desarrollada y comercializada por ICHEME (Institution Of Chemical Engineers).

67 Malaval (1999): Développement Durable, Assurances et Environment. París. Económica. P. 354. 
- Base de datos «The Nacional Response Center» Dependiente de la Agencia de Protección Ambiental de Estados Unidos (US EPA http://www.nrc.uscg.mil/ index.html)

- Base de datos MHIDAS: Major Hazard Incident Data Service. Inicialmente puesta en marcha por el servicio de Seguridad y salud del Reino Unido.

El análisis de estos datos históricos permite aprovechar el efecto experiencia como una herramienta muy eficaz en el estudio del riesgo ambiental, al identificar los factores que han dado lugar a accidentes que han supuesto graves daños humanos, ecológicos y, generalmente, también económicos.

Si bien es cierto, que las bases de datos han mejorado tanto cualitativamente, como cuantitativamente en los últimos años, aún queda un importante camino por recorrer, en el que se puede destacar:

1. Aunque ha mejorado mucho la información, no todos los accidentes recogidos contemplan valoración económica o ambiental de los daños producidos por los accidentes industriales, tanto para la población afectada, como para el medio ambiente, así como su repercusión al patrimonio y al capital productivo de su entorno.

2. No en todos los accidentes estudiados se especifica la causa que lo origina.

3. A la hora de poder definir el «accidente tipo» destacan sobre medida las sustancias empleadas, así como la actividad realizada en el emplazamiento, como dos de los elementos que caracterizadores de estos elementos.

4. Tener en cuenta el entorno del emplazamiento, ya sea rural o urbano y, sus características se ha contemplado como decisivo a la hora de considerar las repercusiones sobre el hombre, ya que la mayor parte de estos accidentes han ocurrido en entornos urbanos.

Las previsiones futuras sobre evaluación de los accidentes ocurridos permiten estimar que dicha evaluación contendrá una mayor cantidad y calidad de datos económicos y ambientales, así como un mayor detalle de las causas que los originan y las circunstancias intrínsecas del accidente. 


\section{LOS PROYECTOS MDL Y LOS RIESGOS AMBIENTALES}

\subsection{Los proyectos $M D L$ y su repercusión por países}

Según la información disponible en la Convención del Cambio Climático de las Naciones Unidas (United Nations Framework Convention on Climate Change), en la actualidad hay unas expectativas de 4200 proyectos MDL que se espera que para el año 2012 supongan 2.900 millones de Certificados de Reducción de Emisiones (CERs).

De ellos, ya hay 1818 proyectos registrados ${ }^{68}$ que suponen 316 millones de Certificados de Reducción de Emisiones (CERs) anuales. Su distribución, según el país anfitrión de la inversión, es la indicada en la Figura 5.

\section{Figura 5}

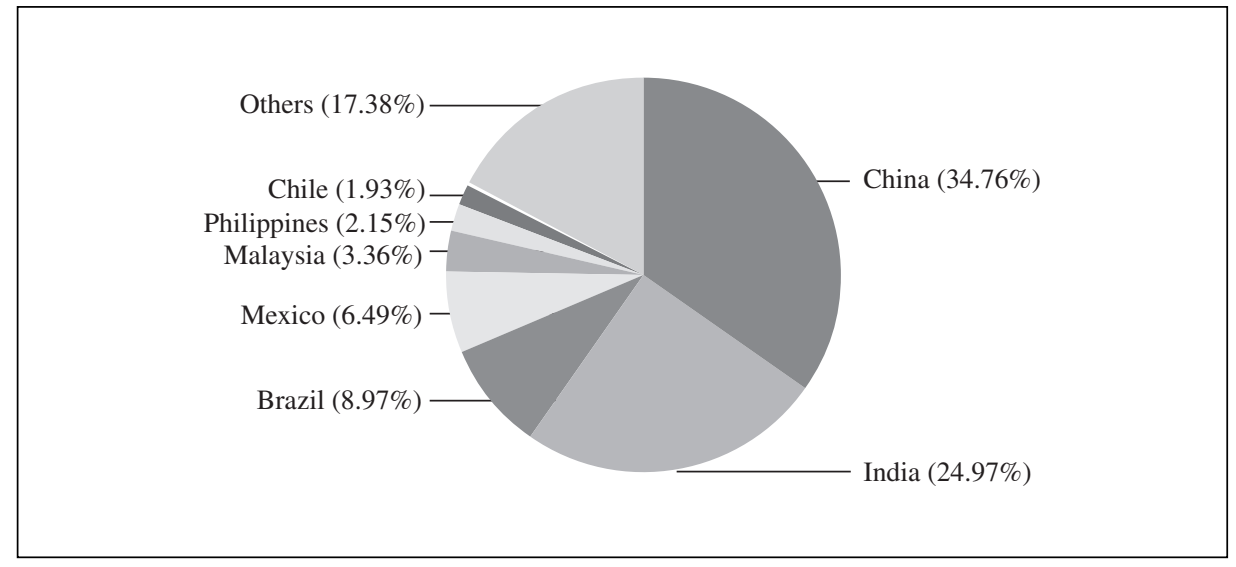

Fuente: UNFCCC.

Casi el $65 \%$ de los proyectos cuentan como país anfitrión de la inversión a China, India o Brasil.

La composición de la procedencia del capital que se invierte en los proyectos MDL, se recoge en la Figura 6.

${ }^{68}$ Datos obtenidos de la web http://cdm.unfccc.int/Statistics/index.html en septiembre de 2009 
Figura 6

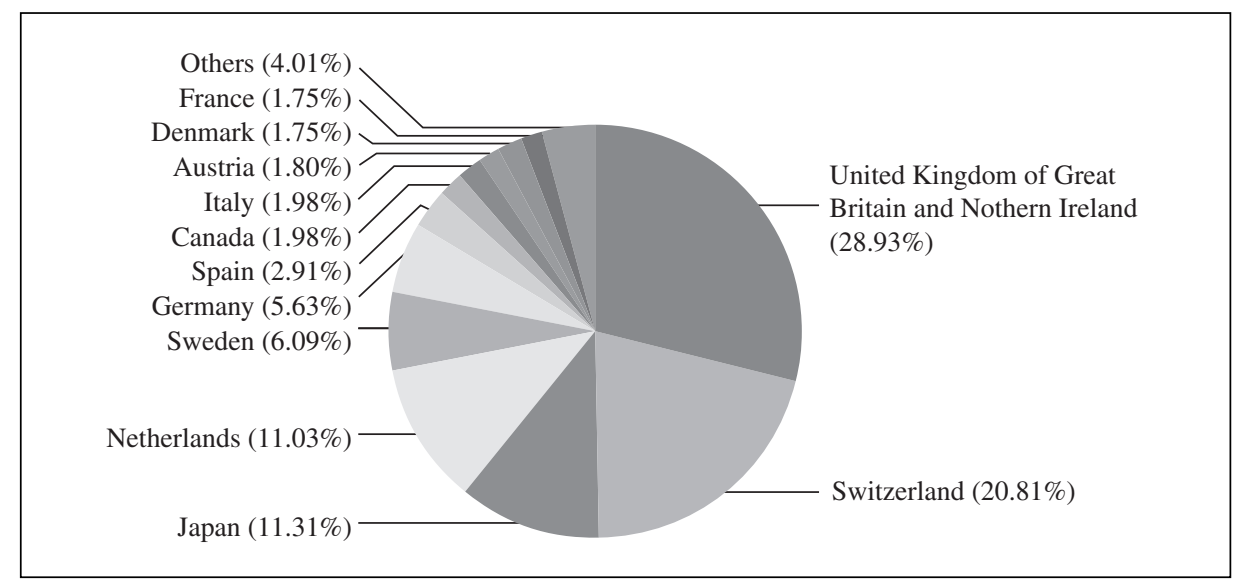

Fuente: UNFCCC.

Por encima del $60 \%$ de los proyectos tiene como origen un país UE, y más del $80 \%$ procede del Continente Europeo.

A la vista de los datos anteriores y teniendo en cuenta que los compromisos adquiridos por la Convención del Cambio Climático de las Naciones Unidas llegan hasta 2012, y dado que estamos ante proyectos de inversión con las vistas puestas a largo plazo, tanto para su ejecución como para la recuperación de la inversión, la UE ha tomado la iniciativa y ha decidido que sus países miembros puedan disfrutar de estas mismas condiciones hasta $2020^{69}$, así como se constituya un fondo común de derechos de emisión para todos sus países miembros y que la asignación de derechos sea por subasta, lo que producirá una sustancial modificación del mercado ${ }^{70}$.

${ }^{69}$ Legislación/ Unión Europea: Decisión No 406/2009/CE del Parlamento Europeo y del Consejo Europeo, de 23 de abril de 2009, sobre el esfuerzo de los Estados Miembros para reducir sus emisiones de gases de efecto invernadero a fin de cumplir los compromisos adquiridos por la Comunidad hasta 2020. DOCE, $\mathrm{N}^{\circ}$ L 140, de 05/06/2009

${ }^{70}$ Legislación/ Unión Europea: Directiva Nº 2009/29/CE del Parlamento Europeo y del Consejo Europeo, de 23 de abril de 2009, por el que se modifica la Directiva2003/87/CE para perfeccionar y ampliar el régimen comunitario de comercio de derechos de emisión de gases de efecto invernadero. DOCE, № L 140, de 05/06/2009. 


\subsection{El papel de los riesgos ambientales en los proyectos $M D L$}

El conocimiento del riesgo de un establecimiento o instalación es un elemento determinante para que los gestores sean conscientes de lo que tienen entre manos y valoren la posibilidad de transferirlos, en qué medida y por cuánto dinero.

Por otra parte, a la hora de plantear nuevos proyectos de inversión, sobre todo de iniciativas productivas que manipulen sustancias consideradas como «peligrosas» 0 realicen actividades productivas «de alto riesgo», deben realizar este tipo de análisis, ya en la fase de diseño del proyecto y de selección de ubicación posible. En ese momento deben evaluar la viabilidad técnica, la viabilidad legal, la viabilidad económica y su viabilidad respecto al riesgo medioambiental que supone. Y todo ello adaptado a las circunstancias locales del emplazamiento elegido a la hora de ubicar el proyecto.

A ello no son ajenos los proyectos de inversión incluidos en el «Clean Development Mechanism», especialmente los que se realicen en países carentes de conocimientos técnicos suficientes y de legislación medioambiental adecuada. Estas iniciativas además de suponer un ahorro y una disminución de los Gases de Efecto Invernadero, proporcionan una transferencia de conocimiento tecnológico a países menos desarrollados, que no deben suponer una «amenaza» ambiental significativa para el país anfitrión o receptor de la inversión.

Existen metodologías apropiadas para evaluar medioambientalmente cualquier proyecto, y más de aquellos proyectos con los que se pretende reducir la emisión de gases a la atmósfera ó potenciar su absorción para atenuar el cambio climático, pero todo ello debe ser complementario a la preocupación por el medio ambiente del país anfitrión. Para ello se debe realizar una evaluación de los riesgos de estas «instalaciones técnicas productivas» sobre el medio ambiente local.

Así al evaluar la viabilidad de un proyecto MDL es necesaria la existencia de de una Evaluación de Riesgos Medioambientales por una entidad independiente.

Esta evaluación debe incluir algunos criterios de riesgo como por ejemplo:

- Las sustancias peligrosas empleadas y/o almacenadas

- La actividad potencialmente contaminante

Además, en términos de riesgo, han de tenerse en cuenta las especificaciones o características del lugar donde se establecerá la actividad. De esa ubicación se deberían considerar: 
- El Medio ambiente próximo y sus características intrínsecas

- La población circundante

- El entorno Socio-Económico

Asimismo se debe tener en cuenta el tamaño del establecimiento o instalación cuyo riesgo se desea evaluar.

Una de las mayores dificultades estriba en definir umbrales claros que delimiten los diferentes niveles de riesgo posible, he aquí un ejemplo de ello fundamentado en Directivas de la Unión Europea, para el caso de las sustancias y de la actividad. Estas Directivas ya han sido transpuestas a la mayor parte de los estados miembros, con ello se pretende tener umbrales nítidos que ayudarán a evaluar el riesgo de estos emplazamientos.

\subsubsection{Niveles de riesgo en función de la actividad}

De acuerdo con la Directiva IPPC pueden diferenciarse, según se indica en la Figura 7 , tres niveles de riesgo atendiendo a la actividad potencialmente contaminante del establecimiento a evaluar.

Figura 7.-Niveles de riesgo en función de la actividad

\begin{tabular}{|l|l|}
\hline \multicolumn{1}{|c|}{ NIVEL DE RIESGO } & \multicolumn{1}{c|}{ ACTIVIDAD } \\
\hline $\mathrm{A}_{1}=$ Riesgo bajo/medio & $\begin{array}{l}\text { Instalaciones cuya actividad no figura en el Anexo I de Directiva } \\
\text { IPPC }\end{array}$ \\
\hline $\mathrm{A}_{2}=$ Riesgo alto & $\begin{array}{l}\text { Instalaciones cuya actividad se incluye en el Anexo I de Directiva } \\
\text { IPPC }\end{array}$ \\
\hline $\mathrm{A}_{3}=$ Riesgo muy alto & $\begin{array}{l}\text { Instalaciones cuya actividad figura en el Anexo I de la Directiva } \\
\text { IPPC y cuentan con una capacidad de producción o rendimiento } \\
\text { superior al umbral definido en la dicha Directiva IPPC }\end{array}$ \\
\hline
\end{tabular}

Fuente: Elaboración propia a partir de la Directiva 96/61/CE del Consejo, de 24 de septiembre de 1996, relativa a la prevención y control integrados de la contaminación.

Si en un mismo emplazamiento se realizan varias actividades de las enunciadas en el Anexo I de la Directiva IPPC, el riesgo total del emplazamiento se obtiene mediante la adicción del riesgo de cada una de ellas. 


\subsubsection{Niveles de riesgo en función de las sustancias procesadas}

Como se refleja en la Figura 8, la Directiva Seveso II define los umbrales de riesgo en función de la cantidad de sustancia peligrosa que se procesa en un establecimiento. El riesgo es menor o mediano cuando la cantidad de sustancia utilizada es menor que un umbral previamente definido, es grande cuando la cantidad de sustancia utilizada está comprendida entre dos umbrales previamente identificados y es muy grande si supera un umbral máximo previamente fijado

Figura 8.-Niveles de riesgo en función de las sustancias procesadas

\begin{tabular}{|c|c|}
\hline NIVEL DE RIESGO & SUSTANCIAS PROCESADAS \\
\hline $\mathrm{S}_{1}=$ Riesgo menor o mediano & Cantidad $<\mathrm{U}_{1}$ \\
\hline $\mathrm{S}_{2}=$ Riesgo grande & $\mathrm{U}_{1} \leq$ Cantidad $<\mathrm{U}_{2}$ \\
\hline $\mathrm{S}_{3}=$ Riesgo muy grande & Cantidad $\geq \mathrm{U}_{2}$ \\
\hline
\end{tabular}

Fuente: Elaboración propia a partir de la Directiva Seveso II.

\subsubsection{Niveles de riesgo en función de la localización del establecimiento}

Con este criterio se toma en consideración que el nivel de riesgo de un establecimiento depende de la densidad de población circundante al establecimiento y de la sensibilidad del entorno de dicho establecimiento.

1. El nivel de riesgo respecto a la población circundante se basa en la densidad de población de la zona donde se ubica el establecimiento industrial, a fin de medir el número de personas que potencialmente se pueden ver afectadas por un accidente cuyo origen se encuentre en dicho establecimiento. A estos efectos, suele considerarse riesgo alto cuando el establecimiento se sitúa en una ciudad (densidad de población $>250$ habitantes $/ \mathrm{km}^{2}$ ), medio si se sitúa en un pueblo (40 habitantes $/ \mathrm{km}^{2}<$ densidad de población $\leq 250$ habitantes $/ \mathrm{km}^{2}$ ) y bajo en zonas rurales (densidad de población $\leq 40$ habitantes $/ \mathrm{km}^{2}$ ). 
2. Entre los criterios generalmente utilizados para analizar la sensibilidad ambiental del entorno del establecimiento se sitúan: las características y propiedades del suelo y del subsuelo donde se ubica el establecimiento; la proximidad de cursos de agua superficial o subterránea y el uso de los mismos (consumo humano, industrial, regadío, etc.); los niveles de contaminación atmosférica en la zona; las características de la flora y la fauna circundantes y la proximidad de parques naturales, zonas de alto interés biológico y patrimonio histórico artístico.

3. Otro criterio de riesgo es análisis de Entorno Socio-Económico donde se prevé ubicar la actividad productiva, para ello se pueden tener en cuenta variables tales como la renta per cápita de la zona, la tasa de desempleo de la zona, como índices de la actividad socioeconómica, sobre todo para ver el grado de desarrollo económico y social, de tal manera que se conceptualice como un desarrollo socio económico, bajo, medio o alto.

\subsubsection{Niveles de riesgo en función del tamaño del establecimiento}

El daño ambiental que puede ocasionar un establecimiento industrial no suele estar relacionado con el valor de las inversiones y la cifra de negocios, sino con variables como la extensión del establecimiento, el número medio de trabajadores, la cantidad media de horas trabajadas al día en el establecimiento y la cantidad media de materiales y productos manipulados al día

El tamaño del establecimiento será mediano o grande cuando reúna al menos dos de las cuatro características indicadas en la Figura 9 y, en el caso de cumplir dos características de cada categoría, se prefiere siempre el mayor de ellos (es decir, un establecimiento que cumple dos criterios de pequeño y otros dos de grande será calificado como grande).

FiguRA 9.-Caracterización del tamaño de un establecimiento

\begin{tabular}{|l|c|c|c|}
\hline \multicolumn{1}{|c|}{ CARACTERÍSTICAS } & PEQUEÑO & MEDIANO & GRANDE \\
\hline $\mathrm{E}=$ Extensión $\left(\mathrm{Km}^{2}\right)$ & $\mathrm{E}<10$ & $50 \leq \mathrm{E}>10$ & $\mathrm{E} \geq 50$ \\
\hline $\begin{array}{l}\mathrm{T}=\text { Número de trabajadores del } \\
\text { emplazamiento (media anual) }\end{array}$ & $\mathrm{T}<50$ & $50 \leq \mathrm{T}<100$ & $\mathrm{~T} \geq 100$ \\
\hline $\begin{array}{l}\mathrm{H}=\text { Horas de actividad al día en el } \\
\text { establecimiento (media anual) }\end{array}$ & $\mathrm{H} \leq 8$ & $8 \leq \mathrm{H}<16$ & $\mathrm{H} \geq 16$ \\
\hline $\begin{array}{l}\mathrm{P}=\text { Número de productos semi-elaborados } \\
\text { manipulados al día en el establecimiento } \\
\text { (media anual) (Tm, } \mathrm{m}^{3} \text { etc.) }\end{array}$ & $\mathrm{P}<10$ & $10 \leq \mathrm{P}<50$ & $\mathrm{P} \geq 50$ \\
\hline
\end{tabular}

Fuente: Elaboración propia. 
La utilización conjunta de estos criterios y sus correspondientes niveles componen el riesgo conjunto. Cada uno de los doce niveles posibles se basa en la adición de los criterios definidos, por lo que han de cuantificarse previamente cada uno de los niveles que configuran los tres criterios considerados como fijos y cada uno de los otros tres que configuran su localización, de la siguiente manera:

FIgURA 10.--Nivel de riesgo sobre el entorno ambiental

\begin{tabular}{|c|c|}
\hline \multirow{3}{*}{ TAMAÑO } & $\mathrm{Z}=$ Pequeño \\
\hline & $\mathrm{Y}=$ Mediano \\
\hline & $\mathrm{X}=$ Grande \\
\hline \multirow{3}{*}{ LOCALIZACIÓN: SENSIBILIDAD DEL ENTORNO } & $\mathrm{E}_{1}=$ Baja \\
\hline & $\mathrm{E}_{2}=$ Media \\
\hline & $\mathrm{E}_{3}=\mathrm{Alta}$ \\
\hline \multirow{3}{*}{ SUSTANCIAS } & $S_{1}=$ Riesgo Menor/ Mediano \\
\hline & $\mathrm{S}_{2}=$ Riesgo Grande \\
\hline & $\mathrm{S}_{3}=$ Riesgo Muy Grande \\
\hline \multirow{3}{*}{ ACTIVIDADES } & $\mathrm{A}_{1}=$ Riesgo Medio/Bajo \\
\hline & $\mathrm{A}_{2}=$ Riesgo Alto \\
\hline & $\mathrm{A}_{3}=$ Riesgo muy Alto \\
\hline
\end{tabular}

Fuente: Elaboración propia.

Así por ejemplo, según se refleja en la Figura 10 un riesgo $\mathrm{XE}_{2} \mathrm{~S}_{1} \mathrm{~A}_{1}$ describe un establecimiento grande, localizado en un entorno medioambiental con sensibilidad mediana, que utiliza sustancias con riesgo menor o mediano y dentro de una actividad con riesgo medio bajo, sobre el entorno medioambiental. 
Figura 11.--Nivel de riesgo sobre el entorno humano

\begin{tabular}{|l|l|}
\hline \multirow{4}{*}{ TAMAÑO } & Z= Pequeño \\
\cline { 2 - 3 } & Y= Mediano \\
\cline { 2 - 3 } & X= Grande \\
\hline \multirow{4}{*}{ LOCALIZACIÓN: POBLACIÓN } & $\mathrm{C}=$ Ciudad \\
\cline { 2 - 3 } & $\mathrm{P}=$ Pueblo \\
\cline { 2 - 3 } & $\mathrm{R}=$ Rural \\
\hline \multirow{4}{*}{ ACTIVIDADES } & $\mathrm{S}_{1}=$ Riesgo Menor/ Mediano \\
\cline { 2 - 3 } & $\mathrm{S}_{2}=$ Riesgo Grande \\
\cline { 2 - 3 } & $\mathrm{S}_{3}=$ Riesgo Muy Grande \\
\hline & $\mathrm{A}_{1}=$ Riesgo Medio/Bajo \\
\cline { 2 - 3 } & $\mathrm{A}_{2}=$ Riesgo Alto \\
\cline { 2 - 3 } & $\mathrm{A}_{3}=$ Riesgo muy Alto \\
\hline
\end{tabular}

Fuente: Elaboración propia.

O según se refleja en la Figura 11, un riesgo $\mathrm{XCS}_{1} \mathrm{~A}_{1}$ describe un establecimiento grande, localizado en el entorno en una ciudad, que utiliza sustancias con riesgo menor o mediano y dentro de una actividad con riesgo medio bajo, sobre el entorno humano 
Fugura 12.--Nivel de riesgo sobre el entorno socioeconómico

\begin{tabular}{|l|l|}
\hline \multirow{4}{*}{ TAMAÑO } & Z= Pequeño \\
\cline { 2 - 3 } & Y= Mediano \\
\cline { 2 - 3 } & $\mathrm{X}=$ Grande \\
\hline \multirow{4}{*}{ LOCALIZACIÓN: SOCIO-ECONÓMICO } & $\mathrm{J}_{1}=$ Bajo \\
\cline { 2 - 3 } & $\mathrm{J}_{2}=$ Medio \\
\cline { 2 - 3 } & $\mathrm{J}_{3}=$ Alto \\
\hline \multirow{5}{*}{ SUSTANCIAS } & $\mathrm{S}_{1}=$ Riesgo Menor/ Mediano \\
\cline { 2 - 3 } & $\mathrm{S}_{2}=$ Riesgo Grande \\
\cline { 2 - 3 } & $\mathrm{S}_{3}=$ Riesgo Muy Grande \\
\hline & $\mathrm{A}_{1}=$ Riesgo Medio/Bajo \\
\cline { 2 - 3 } & $\mathrm{A}_{2}=$ Riesgo Alto \\
\cline { 2 - 3 } & $\mathrm{A}_{3}=$ Riesgo muy Alto \\
\hline
\end{tabular}

Fuente: Elaboración propia.

Por último, en la Figura 12, un riesgo $\mathrm{XJ}_{3} \mathrm{~S}_{1} \mathrm{~A}_{1}$ describe un establecimiento grande, con un desarrollo socio-económico alto, que utiliza sustancias con riesgo menor o mediano y dentro de una actividad con riesgo medio bajo, sobre el entorno socio económico.

Esta determinación del nivel de riesgo de una instalación industrial es un primer acercamiento a la posibilidad de su aseguramiento, por lo que convendrá tener en cuenta otros factores, como por ejemplo la gestión de los riesgos ambientales que realice el establecimiento industrial, la adecuación a la normativa vigente, etc.

\section{Conclusiones}

- La realización de inversiones en desarrollo limpio supone un aumento de la actividad económica en los países anfitriones, así como inversiones en tecnologías respetuosas con el medioambiente. 
- La implantación de Proyectos de Desarrollo Limpio (MDL), por parte de la Convención sobre el Cambio Climático, ha supuesto que se hayan registrado de 1.832 proyectos de este tipo ${ }^{71}$, atendiendo al país anfitrión de la inversión.

- Estos proyectos suponen una disminución de las emisiones o una absorción de gases de efecto invernadero, al auspiciar la ONU la utilización de las Mejores Técnicas Disponibles (BAT).

- Una propiedad de este mecanismo, es que una vez determinadas la Reducción Certificada de Emisiones (RCE's) por cada proyecto, los promotores pueden trasladar esos certificados a terceros países.

- La posibilidad de trasladar los RCE's, ha supuesto una movilización del capital en los países desarrollados, especialmente en Europa, convirtiéndose en promotores de proyectos MDL en países como China, India o Brasil, que concentran en torno al $70 \%$ de los proyectos.

- La UE, ha decido extender este régimen hasta 2020, buscando dar un marco de estabilidad, jurídica, económica y financiera a los promotores de sus países miembros.

- La utilización de la evaluación de riesgos permite realizar comparaciones una vez definidos los entornos, cuestión que no tienen en cuenta otras metodologías.

- Los países anfitriones, en muchos casos, no poseen ni los conocimientos ni la preparación adecuada, sobre todo en las fases iniciales de la implantación de este tipo de proyectos, para contar con toda la información posible en el proceso de toma de decisiones. Ante ello, estos países se ven obligados a recurrir a expertos internacionales independientes, para que les ayuden en este proceso.

- La selección de emplazamientos adecuados para este tipo de proyectos, debe tener en cuenta la «sensibilidad al entorno humano, al entorno medioambiental y al entorno socio-económico», así como la influencia que sobre estos entornos tienen las sustancias procesadas, los procesos productivos llevados a cabo así como la intensidad en su utilización.

- Lo anteriormente descrito nos lleva a una Evaluación de los Riesgos Medioambientales de los proyectos MDL, sobre los tres entornos descritos. Esta es una metodología muy extendida entre el Sector Asegurador y con un consenso bastante amplio recogido en la norma UNE 150.008 y debería ser un experto inde-

${ }^{71}$ http://cdm.unfecc.int/(c) 28.09.2009 
pendiente, de gran prestigio internacional, quien de manera objetiva realizara este tipo evaluaciones ante las carencias de determinados países anfitriones.

- El promotor tratará de escoger el emplazamiento más beneficioso para su proyecto, es decir el que suponga una menor inversión o por ejemplo una mayor productividad a un menor coste. Pero seguramente este emplazamiento no coincida con el que más le interese al país anfitrión, de ahí la importancia de este tipo de análisis.

- Estas inversiones, además de estar enfocadas a tener una larga vida útil, la cuantía de la inversión inicial suele ser muy elevada, por lo que necesita largos períodos de tiempo para recuperar la inversión inicial. Ante ello es más que recomendable utilizar las mejores tecnologías disponibles, en cada momento del tiempo, buscando que no queden obsoletas en pocos años, dadas las repercusiones económicas y medioambientales que esto pudiera tener.

\section{REFERENCIAS BIBLIOGRÁFICAS}

AENOR (2000): UNE 150.008 Análisis y Evaluación del Riesgo Medioambiental. Madrid. AENOR.

- (2008): UNE 150.008 Análisis y Evaluación del Riesgo Medioambiental. Madrid. AENOR. Agencia Europea de Medio Ambiente (1998): Medio Ambiente en Europa: El Informe Dobris. Madrid. Oficina de Publicaciones Oficiales de las Comunidades Europeas y Ministerio de Medio Ambiente. Madrid Edición original editada en 1995.

- (1999): El Medio Ambiente en la Unión Europea en el umbral del Siglo XXI; resumen. Copenhague. http://www.eea.eu.int

- (2000): Environmental signals 2000. http://themes.eea.ue.int/showpage .php/?pg=40635

American Institute of Chemical Egineers (AICI) (1995): Guidelines of Chemical Transportation Risk Analysis. New York. Ed. AICI.

Azquieta Oyarzun (1.995): Valoración Económica de la Calidad Ambiental. Madrid. Editorial Mc Graw Hill

Cabezas Ares (2003): Los Seguros de Responsabilidad Civil Medioambiental en la Industria. León. Servicio de Imprenta. Secretariado de Publicaciones y Medios Audiovisuales. Universidad de León.

CASAl (1991): La Evaluación del riesgo en la industria química. Jornadas sobre impacto ambiental en la Industria Química. El Escorial, Madrid. Agosto de 1991

Conesa Fernández-Vítora (1997): Los instrumentos de la Gestión Ambiental en la Empresa. Madrid. Ed. Mundi-Prensa. 
Davies (1996): Comparing Environmental Risks: Tools for Setting Government Priorities. Washington, D.C. Ed. Resources for the Future.

Dirección General de Protección Civil y Emergencias (2004). Guía técnica para la realización del análisis de riesgo medioambiental, en el ámbito del Real Decreto 1254/1999 (Seveso II). Madrid. www.proteccióncivil.org.

- Metodología para el Anaíisis de riesgos Ambientales en el marco de la Directiva Comunitaria 96/82/CE_ (Seveso II). Madrid. www.proteccióncivil.org

- (2002).Guía para la realización del análisis del riesgo medioambiental (en el ámbito del Real Decreto 1254/99 [Seveso II]) Madrid. www.proteccióncivil.org

- (2004).Guía técnica para Casos prácticos de Análisis del riesgo (en los establecimientos de nivel inferior de afectación en el ámbito del Real Decreto 1254/99 [Seveso II]). Madrid. www.proteccióncivil.org

Enviromental Protection Agency (EPA). Office of Policy Analysis (1987): Unfinished Business: A Comparative Assessment of Environmental Problems. Washington, D.C. Ed U.S. EPA.

FAIRMAN y otros (1998): Evaluación del riesgo Medioambiental: Enfoque, Experiencias y Fuentes de Información. Copenhague. Agencia Europea del Medio Ambiente.

Fernández Cuesta y Fronti de García (2008): «Control económico de proyectos para sostenibilidad ambiental». Comisión de Contabilidad de Gestión de A.E.C.A. vol. XXIII. № 81. págs. 1011-1033.

FERnÁNDEZ Moro (1.999): «El mapa de riesgo de negocio: bases para su elaboración». Revista

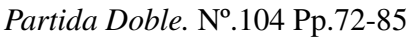

Fundación Entorno Empresa y Medio Ambiente (1999): El Riesgo Medioambiental en la Industria. Madrid. Fundación Entorno.

- (1999): Las entidades Financieras y de Seguros y su Compromiso con el Medio Ambiente. Madrid. Publicación Fundación Entorno.

- (1999): Análisis del Ciclo de Vida: Nuevas herramientas para la Gestión Ambiental Empresarial. Madrid. Fundación Entorno.

Imperial College/HMIP (1995): Link Research Project. Pollution Risk Assessment Techniques for Non-Routine Releases from Industrial Processes. Londres. Imperial College/HMIP \& DVD Technica.

Instituto de Investigaciones Ecológicas (1997): Master en Consultoría y Verificación Medioambiental; Málaga Ed. Gráficas Centauro S.L.

ITSEMAP Ambiental (1994): Criterios y Sistemática de Evaluación del Riesgo Medioambiental (Pool de Riesgos Medioambientales). Madrid. ITSEMAP

- (1994): Estudio del sector Medioambiental en España. Madrid. Ed. Mapfre. 
ITSEMAP Ambiental (1997): Riesgos Ambientales en el Industria. Prevención y Mitigación de Daños. Madrid. Ed Mapfre

Jan Peter Six (1998): EU White Paper on Environmental Liability (Top Priority for General Liability Insurers). París. Prepared for the OCDE.

KPMG (2008): KPMG International Survey of Corporate Responsibility Reporting 2008. http:// www.kpmg.com/Global/IssuesAndInsights/ArticlesAndPublications/Pages/Sustainabilitycorporate-responsibility-reporting-2008.aspx

LANDUlCE (1991): «El riesgo de un accidente es imposible llevarlo a cero». Química Hoy. Enero. $N^{o} 8$ págs. $45-47$

Malaval (1999): Développement Durable, Assurances et Environnenment. París. Ed. Economica

National Academy of Sciences (NAS). Committee on the Institutional Means for AsSESSMEnt on Risks to Public Health (1983): Risk Assessment in the Federal Government: Managing the Process. Washington. NAS.

Newland (1996): «Lead Paint Hazards». Risk Management. September. Pp.35-38.

OCDE (1972):Recomendación de la OCDE C-72-126 de 26 de mayo de 1972

- (1992):. Principios guías para la prevención de accidentes químicos, preparación y respuesta. Monografía Medioambiental № 51. París. OCDE.

- (1997): Report of the OECD Workshop on Risk Assessment and Risk Communication in the Context of Chemical Accident Prevention, Preparedness and Response. París Ed.OCDE

Organización Internacional del Trabajo (OIT) (1991): Prevención de Accidentes Industriales Mayores. Ginebra. OIT

Peñalver Cámara (1990): La Protección del Medio Ambiente ante los Accidentes Mayores en la Industria. Seminario la Prevención de Accidentes Mayores en la Industria, Madrid 11-13 de Septiembre. Ciemat.

Pietersen (1990): Technical Tools for Risk Assessment. Seminario la Prevención de Accidentes Mayores en la Industria, Madrid 11-13 de Septiembre. Ciemat.

Pitbaldo y Turney (1996): Risk Assessment in the Process Industries. Rugby. IACI.

Seonnez Calvo (1995): El Gran Diccionario del Medio Ambiente y de la Contaminación. Madrid. Ed. Mundi Prensa.

SNyder y Smith (1994): «The Industry's Black Hole». Best's Review. Mayo. págs. 7-27

Unión Europea (1973): Primer Programa de acción en materia de medio ambiente. DOCE C $\mathrm{N}^{\mathrm{o}} 112$, de $20 / 12 / 1973$

- (1977): Segundo Programa de acción en materia de medio ambiente. DOCE C No 139, de $13 / 06 / 1977$

- (1978): El lugar y el papel de una política preventiva del medio ambiente en un desarrollo armónico de las actividades económicas en el Conjunto de a Comunidad. COM (78)601 Final, de 15/11/1978 
Unión Europea (1983): Tercer Programa de acción en materia de medio ambiente. DOCE C 46, de 17/02/1983

- (1987): Cuarto Programa de acción en materia de medio ambiente. DOCE C 289, de 29/10/1987

- (1992): Quinto Programa comunitario para el medio ambiente: Hacia un desarrollo sostenible COM (92) 23 Final.

- (1993):Libro Verde sobre la Reparación del Daño Ecológico. Comunicación de la Comisión al Consejo, al Parlamento y al Comité Económico y Social. COM (93)-47 Final. Bruselas 14/05/1993.

- (1995): Informe sobre la aplicación del Programa Comunitario de política y Actuación en materia de Medio Ambiente y Desarrollo Sostenible. Hacia un Desarrollo Sostenible COM (95)624 Final de 10/01/1996

- (1996): Oficina de Riesgos Ambientales Graves. COM (96) No 7 Final. Bruselas.09/02/96

- (1999): El medio ambiente en Europa: Hacia dónde encauzar el futuro. Com (1.999) $\mathrm{N}^{\circ}$ 543-Final.

- (1999): L'Ecenomie de L'Unión: Bilan de 1.999. Bruselas.

- (2000): Libro Blanco sobre Responsabilidad Ambiental. Comunicación de la Comisión al Consejo, al Parlamento y al Comité Económico y Social. COM (2000)66 Final. Bruselas 09/02/2000.

- (2000): Data for short-term economic analysis. Eurostatistics $N^{o} 7$. Luxemburgo.

- (2000): Posición Común del Consejo de modificación parcial del Reglamento EMAS, de 28 de Febrero de 2000. DOCE de 8/05/2000.

- (2001): Sexto Programa de Acción de la Comunidad Europea en materia de Medio Ambiente: «Medio Ambiente 2010: el futuro está en nuestras manos». COM (2001) 31 final. http:// europa.eu.int/comm/environment/newprg/index.htm.

- (2001): Trabajos preparatorios del $6^{\circ}$ PAMA. Dirección General de Medio Ambiente. http:// europa.ue.int/comm/ environment/newprg/index.htm.

Unión Europea / Parlamento Europeo (1992): Documento No A3-0380/92; la resolución del Parlamento Europeo sobre la aplicación del principio de subsidiariedad en materia de política medioambiental, de 19 de febrero de 1993, DOCE n ${ }^{\circ}$ C42/40, de 15/02/1993.

Vázquez Cobos y Poveda Gómez (1998): El Control de los Riesgos Ambientales. Publicación Oficial del IV Congreso Nacional del Medio Ambiente. Colegio Oficial de Físicos. Vol no3 págs. 540-559

Verger (1983): Risk Management: nueva estrategia empresarial. Barcelona.. Ed. Hispano Europea

Villamil y Maties (1998): Política económica del medio ambiente. Aplicaciones empresariales. Centro de Estudios Ramón Areces. Madrid. Colección Ceura-Economía. págs. 45-69. 
VRом (1990): Premises for Risk management, risk limits in the context of environmental policy. In: Environmental Policy Plan «Keizen of Verliezen» (Second Chamber of the States General, 1988-89 session, 211137). The Hague. The Netherlands, Ministry Of Housing, Physical Planning and Environment.

Winans (1997): «Setting the Standard». Best's Review. April. Pp.32-35

World Health Organization (1996): Linkage Methods for Environmental and Health Analysis. Geneve. Office Of Global And Integrated Environmental Health. WHO.

ZUPKA (1997): «Experiencias en la mitigación de desastres naturales» Gerencia de riesgos $n^{\circ}$ 59; Madrid págs. 9-17

\section{Normativa}

Legislación/ España: Real Decreto 886/1988, de 15 de junio, sobre prevención de accidentes mayores en determinadas actividades industriales. BOE N 187 de 5/08/1.988

Legislación/ España: Ley 30/1995 de 8 de Noviembre, Ley de Ordenación y Supervisión de los Seguros Privados BOE No 265 09/11/1995.

Legislación/ España: Real Decreto 1254/1999, de 16 de julio, por el que se aprueban medidas de control de los riesgos inherentes a los accidentes graves en los que intervengan sustancias peligrosas. BOE $\mathrm{N}^{\circ} 172$ de 20/07/1999.

Legislación/ España: Resolución de 16 de marzo de 2000, de la Dirección General de Industria y Tecnología, por la que se modifica la de 29 de Septiembre de 1999, por la que se someten a información pública los proyectos de normas UNE que AENOR tiene en tramitación, correspondientes al mes de agosto de 1999. BOE $\mathrm{N}^{\circ} 77$, de 30/03/2000.

Legislación/ España: Ley 16/2002, de 1 de julio, de Prevención y Control Integrado de la Contaminación. BOE No 157 02/07/2002

Legislación/ España: Real Decreto 119/2005, de 4 de febrero, por el que se aprueban medidas e control de los riesgos inherentes a los accidentes graves en los que intervengan sustancias peligrosas, BOE No 36 de 11/02/2005 modificando el Real Decreto 1254/1999, de 16 de julio, por el que se aprueban medidas de control de los riesgos inherentes a los accidentes graves en los que intervengan sustancias peligrosas. BOE N 172 de 20/07/1999.

Legislación/ España: Real Decreto 948/2005, de 29 de julio, por el que se aprueban medidas e control de los riesgos inherentes a los accidentes graves en los que intervengan sustancias peligrosas, BOE Nº 181 de 30/07/2005 modificando el Real Decreto 1254/1999, de 16 de julio, por el que se aprueban medidas de control de los riesgos inherentes a los accidentes graves en los que intervengan sustancias peligrosas. BOE N 172 de 20/07/1999. 
Legislación/ España: Ley 1/2005, de 9 de marzo, por la que se regula el régimen del comercio de derechos de emisión de gases de efecto invernadero. BOE N 59 10/03/2005

Legislación/ España: Real Decreto 509/2007, de 20 de abril, por el que se aprueba el reglamento para el desarrollo y ejecución de la Ley 16/2002, de 1 de julio, de prevención y control integrado de la contaminación. BOE No 96 21/04/2007

Legislación/ España: Real Decreto 1030/2007, de 20 de julio, por el que se modifica el Real Decreto 1370/2006, de24 de noviembre, por el que se aprueba el Plan Nacional de Asignación de derechos de emisión de gases de efecto invernadero, 2008-2012. BOE No 174 21/07/2005

Legislación/ España: Real Decreto 1031/2007, de 20 de julio, por el que se desarrolla el marco de participación en los mecanismos de flexibilidad del Protocolo de Kioto. BOE $\mathrm{N}^{\mathrm{o}} 174$ $21 / 07 / 2005$

Legislación/ España: Ley 26/2007, de 23 de octubre, de Responsabilidad Medioambiental. BOE $\mathrm{N}^{\circ} 25524 / 10 / 2007$

Legislación/ España: Real Decreto 1402/2007, de 29 de octubre, por el que se modifica el Real Decreto 1370/2006, de 24 de noviembre, por el que se aprueba el Plan Nacional de Asignación de derechos de emisión de gases de efecto invernadero, 2008-2012. BOE $\mathrm{N}^{\circ} 260$ $30 / 10 / 2007$

Legislación/ España: Ley 5/2009, de 29 de junio, por la que se modifican la Ley 24/1988, de 28 de julio, del mercado de valores, la Ley 26/1988, de 29 de julio, sobre disciplina e intervención de las entidades de crédito y el texto refundido de la Ley de ordenación y supervisión de los seguros privados, aprobado por Real Decreto Legislativo 6/2004, de 29 de octubre, para la reforma del régimen de participaciones significativas en empresas de servicios de inversión, en entidades de crédito y en entidades aseguradoras(La disposición adicional segunda establece obligaciones de informaciónpara sectores que se incorporan al régimen de comercio de derechos de emisión de gases de efecto invernadero). BOE No 157 30/06/2009

Legislación/ Unión Europea: Directiva 1982/501/CEE, del Consejo de 24 de junio, relativa a los riesgos de accidentes graves en determinadas actividades industriales DOCE No L 230 de $5 / 08 / 1982$

Legislación/ Unión Europea: Directiva 1996/82/CE del Consejo, de 9 de Diciembre de 1996, relativa al control y riegos inherentes a los accidentes graves en los que intervengan sustancias peligrosas. DOCE, $\mathrm{N}^{\circ}$ L 10, de 14/01/1997.

Legislación/ Unión Europea: Reglamento (CEE) No 3037/1990, del Consejo, de 9 de octubre de 1990, relativo a la nomenclatura estadística de actividades económicas en la Comunidad Europea DOCE Nº L 293 de 24/10/1990.

Legislación/ Unión Europea: Reglamento (CEE) No 1836/1993 del Consejo, de 29 de junio de 1993, por el que se permite que las empresas del sector industrial se adhieran con carácter 
voluntario a un sistema comunitario de gestión y auditoría medioambientales DOCE L N ${ }^{\circ}$ 168 de 10/07/1993

Legislación/ Unión Europea: Directiva 1996/61/CE del Consejo, de 24 de Septiembre de 1996, relativa a la prevención y control integrados de la contaminación. DOCE $\mathrm{N}^{\circ} \mathrm{L} 257$ de 10/10/1996

Legislación/ Unión Europea: Reglamento (CE) N 761/2001 del Parlamento Europeo y del Consejo Europeo, de 19 de marzo de2001, por el que se permite que las organizaciones se adhieran con carácter voluntario a un sistema comunitario de gestión y auditoría medioambientales (EMAS). DOCE L No 114 de 24/04/2001

Legislación/ Unión Europea: Directiva 2003/04/CE del Parlamento Europeo y del Consejo, de 28 de Enero de 2003, relativa al acceso del público a la información medioambiental y por la que se deroga la directiva 90/313CEE del Consejo. DOCE, № L 41, de 14/02/2003.

Legislación/ Unión Europea: Directiva 2003/87/CE del Parlamento Europeo y del Consejo, de 13 de octubre de 2003, por la que se establece un régimen para el comercio de derechos de emisión de gases de efecto invernadero en la Comunidad y por la que se modifica la Directiva 96/61/CE del Consejo. DOCE L No 275 de 25/10/2003.

Legislación/ Unión Europea: Directiva 2003/105/CE del Consejo, de 16 de Diciembre de 2003 DOCE, $N^{\circ}$ L 345, de 31/12/2003 por la que se modifica la Directiva 96/82/CE del Consejo, de 9 de Diciembre de 1996, relativa al control y riegos inherentes a los accidentes graves en los que intervengan sustancias peligrosas. DOCE, $\mathrm{N}^{\circ}$ L 10, de 14/01/1997.

Legislación/ Unión Europea: Decisión 280/2004/CE, del Parlamento Europeo y del Consejo, de 11 de febrero de 2004 relativa a un mecanismo para el seguimiento de las emisiones de gases de efecto invernadero en la Comunidad y para la aplicación del Protocolo de Kyoto. DOCE, $\mathrm{N}^{\circ} \mathrm{L} 49$, de 19/02/2004.

Legislación/ Unión Europea: Directiva 2004/35/CE del Parlamento Europeo y del Consejo, de 21 de Abril de 2004, sobre responsabilidad medioambiental en relación con la prevención y reparación de daños ambientales. DOCE, Nº L 143, de 30/04/2004.

Legislación/ Unión Europea: Directiva No 2009/29/CE del Parlamento Europeo y del Consejo Europeo, de 23 de abril de 2009, por el que se modifica la Directiva2003/87/CE para perfeccionar y ampliar el régimen comunitario de comercio de derechos de emisión de gases de efecto invernadero. DOCE, $\mathrm{N}^{\circ}$ L 140, de 05/06/2009.

Legislación/ Unión Europea: Decision No 406/2009/CE del Parlamento Europeo y del Consejo Europeo, de 23 de abril de 2009, sobre el esfuerzo de los Estados Miembros para reducir sus emisiones de gases de efecto invernadero a fin de cumplir los compromisos adquiridos por la Comunidad hasta 2020. DOCE, Nº L 140, de 05/06/2009

Legislación/ Naciones Unidas: Convención Marco de las Naciones Unidas sobre el cambio Climático (1992) 
Legislación/ Naciones Unidas: Protocolo de Kyoto (1997)

Legislación/ Naciones Unidas: Acuerdo político de Buenos Aires (1999)

Legislación/ Naciones Unidas: Acuerdo Político de Bonn (2001)

Legislación/ Naciones Unidas: Acuerdos de Marrakech (2002)

Legislación/ Naciones Unidas: Conferencia del Cambio Climático Ponzan (2008)

\section{DIRECCIONES WEB DE INTERÉS}

http://www.europa.eu

http://www.fundacionentorno.org

http://www.oecd.org

http://www.un.org

http://www.unep.org

http://www.eea.europa.eu

http://www.unep.org/labour_environment/

http://www.grupimedes.com/imedes.html

http://www.ecoempleo.com/

http://www.eustat.es

http://www.unfccc.org

http://www.epa.gov

http://www.perm.es

http://www.unfccc.org

http://www.marm.es 